\title{
Treack or trit: Adaptation to genuine and arbitrary foreign accents by monolingual and bilingual listeners
}

\author{
Andrea Weber ${ }^{a, b, c, *}$, Anna Maria Di Betta ${ }^{d}$, James M. McQueen ${ }^{a, e}$ \\ a Max Planck Institute for Psycholinguistics, Nijmegen, The Netherlands \\ ${ }^{\mathrm{b}}$ Donders Institute for Brain, Cognition, and Behaviour, Radboud University Nijmegen, Nijmegen, The Netherlands \\ ${ }^{\mathrm{c}}$ Eberhard-Karls Universität Tübingen, Germany \\ d Sheffield Hallam Univesity, Sheffield, United Kingdom

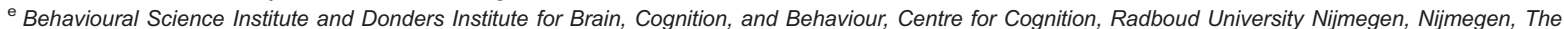 \\ Netherlands
}

\section{A R T I CLE I NFO}

\section{Article history:}

Received 16 May 2013

Received in revised form

20 May 2014

Accepted 29 May 2014

\section{Keywords:}

Adaptation

Foreign accents

Spoken-word recognition

Native listening

Nonnative listening

Italian

English

Dutch

\begin{abstract}
A B S T R A C T
Two cross-modal priming experiments examined two questions about word recognition in foreign-accented speech: Does accent adaptation occur only for genuine accents markers, and does adaptation depend on language experience? We compared recognition of words spoken with canonical, genuinely-accented and arbitrarily-accented vowels. In Experiment 1, an Italian speaker pronounced vowels in English prime words canonically, or by lengthening /I/ as in a genuine Italian accent ( ${ }^{*} /$ tri:k/ for trick), or by arbitrarily shortening /i:/ (*/trtt/ for treat). Lexical-decision times to subsequent visual target words showed different priming effects in three listener groups. Monolingual native English listeners recognized variants with lengthened but not shortened vowels. Bilingual nonnative Italian-English listeners, who could not reliably distinguish vowel length, recognized both variants. Bilingual nonnative Dutch-English listeners also recognized both variants. In Experiment 2, bilingual Dutch-English listeners recognized Dutch words with genuinely- and arbitrarily-accented vowels (spoken by a native Italian with lengthened and shortened vowels respectively), but recognized words with canonical vowels more easily than words with accented vowels. These results suggest that adaptation to genuine accent markers arises for monolingual and bilingual listeners alike and can occur in native and nonnative languages, but that bilinguals can adapt to arbitrary accent markers better than monolinguals.
\end{abstract}

\section{Introduction}

In 2010, a new restaurant named Eataly opened in New York. The name is a clever wordplay for an Italian eatery; one can almost hear the supposedly Italian owner pronouncing the name of his or her country of birth. The reason for this is that lengthening the short vowel /I/ in Italy is typical of an Italian accent in English (see e.g., Duguid, 2008). Listeners' awareness of foreign accents in speech has received considerable attention in speech research for a number of years (e.g., Flege, Munro, \& MacKay, 1995; Munro, Derwing, \& Burgess, 2010). Less attention has been paid to the question of what a foreign accent means for language comprehension (for a recent review see, Cristia et al., 2012). How does prior language experience shape the way listeners adapt to a foreign accent? And how important is it for understanding that a specific accent marker is genuine, and hence consistent with prior experience with that accent? In the present study, these questions will be addressed through two experiments, one on Italian-accented English and one on Italian-accented Dutch.

\subsection{Adapting to foreign accents}

In foreign-accented speech, listeners are confronted with a speech signal that reflects language-specific structures from the speaker's native language. In the Eataly example, the vowel lengthening of the initial /I/ reflects the fact that the only high front vowel in Italian is the long vowel /i/, whereas English also has short/I/ (e.g., Agard \& di Pietro, 1969; Giegerich, 1992). Understanding

\footnotetext{
* Correspondence to: University of Tübingen, Philosophische Fakultät, Wilhelmstrasse 50, 72074 Tübingen, Germany. Tel.: +49 70712978464.

E-mail address: andrea.weber@uni-tuebingen.de (A. Weber).
} 
foreign-accented speech requires the speech-recognition system to adapt to these nonnative pronunciation variations. Research on the recognition of native pronunciation variations suggests that this may indeed be possible: native listeners can retune their categories to include phonological variants after brief exposure to variant forms (e.g., Kraljic \& Samuel, 2005; Norris, McQueen, \& Cutler, 2003). In these studies, adult native listeners are first exposed to words in which one of two sounds is ambiguous (e.g., either all /s/ or all /f/ sounds in words are realized halfway between /s/ and /f/). In a subsequent test phase, listeners categorize ambiguous sounds more often as the sound that was ambiguous during exposure (i.e., they make more /f/ responses when, during exposure, words with /f/ were ambiguous). The perceptual retuning that occurs in the exposure phase also influences how listeners recognize other words (McQueen, Cutler, \& Norris, 2006); this is thus evidence that the adaptation is beneficial to speech perception, helping listeners tune in to unusual yet native pronunciations.

The question then is whether the speech-recognition system demonstrates similar beneficial flexibility in response to foreignaccented speech. Note that in the Eataly example the situation is quite different from that in the native-language perceptual retuning studies. First, listeners do not have to adapt to bad exemplars of a segmental category that do not clearly belong to one category or another. Instead, they hear good examples of a different segmental category (in the Eataly example the long vowel /i:/) and have to learn to interpret variant forms which contain that segment in an appropriate way at the lexical level (in the Eataly example interpret /i:teli/ as Italy). Second, variation in nonnative speech is not restricted to single segments. Instead, the language background of a nonnative speaker is perceptible on most segments of his or her speech as well as on the suprasegmental level (e.g., Gut, 2012). This could have a detrimental effect on adaptation, because lexical processing may thus be more difficult in foreign-accented speech (e.g., Floccia, Butler, Goslin, \& Ellis, 2006). Alternatively, however, it could help adaptation. If listeners consider variation as a general characteristic of nonnative speakers they could be more likely to accommodate to such speakers' ways of talking as compared to when they do not consider it a general characteristic.

There is indeed evidence showing that we get better at understanding foreign-accented speech the more we hear it (e.g., Bradlow \& Bent, 2008; Clarke \& Garrett, 2004; Sidaras, Alexander, \& Nygaard, 2009; but see Floccia et al., 2006). In Clarke and Garrett (2004), for example, English listeners had to decide whether a visually presented word was part of a sentence they had just heard. The sentences were either spoken by a Spanish learner of English or by a native speaker of English. While decision times were initially slower for Spanish-accented sentences, this disadvantage had disappeared when the listeners were tested after one minute of exposure. Thus listeners can apparently ease into the global foreign accent of a speaker very rapidly. Adaptation furthermore occurs regardless of a nonnative speaker's baseline intelligibility, although it takes longer for less intelligible speakers (e.g., Adank, Evans, StuartSmith, \& Scott, 2009; Bradlow \& Bent, 2008).

\subsection{Genuinely-accented vs. arbitrarily-accented pronunciations}

Listeners therefore can adapt to foreign-accented speech. But much still remains to be discovered about the nature of this adaptation. We ask here, for example, whether the genuineness of accent markers influences the recognition of foreign-accented words. Research on native speech recognition has shown that listeners succeed in recognizing canonical forms, but often fail to interpret variant forms correctly. Using a variety of tasks, studies on variation in native speech have shown that word recognition is not only sensitive to smaller sub-phonetic mismatches (e.g., Andruski, Blumstein, \& Burton, 1994; Marslen-Wilson \& Warren, 1994; McQueen, Norris \& Cutler, 1999; Whalen, 1991) but also that, in the case of larger phonetic dissimilarity between canonical and mispronounced sounds, listeners may fail in recognizing the intended word (e.g., Connine, Blasko, \& Titone, 1993; Marslen-Wilson, Moss, \& Van Halen, 1996). These studies on native speech, however, used arbitrary variation - that is, the substitution of one phoneme by another that, though controlled (e.g., in number of mismatching features), was not motivated by phonological processes within the language in question and was thus unknown to the participants (e.g., /v/ in never was changed to /z/ in Connine et al., 1993). If the arbitrariness of a mispronunciation matters to listeners, then they should fail to recognize forms in foreign-accented speech which are arbitrary in the accent they are listening to (e.g., an Italian shortening the stressed vowel in eatery to Itary) but may succeed if the forms are a genuine feature of that accent (e.g., an Italian lengthening the stressed vowel in Italy to Eataly). Indeed, for genuine variant forms, Witteman, Weber, and McQueen (2013) have recently shown that listeners can recognize genuine variants forms when listeners are familiar with the accent or when accent strength is moderate (see also Weber, Broersma, \& Aoyagi, 2011). In order to investigate the role of genuineness further, we compared the recognition of foreign-accented words with genuine accent markers with that of foreign-accented words with arbitrary accent markers.

\subsection{Prior language experience}

If listeners can successfully recognize words containing genuine markers of an Italian accent, and fail on words with substitutions that are arbitrary in an Italian accent, then this would suggest that prior experience with foreign-accented words modulates the adaptation process. It has been found that long-term experience with native variant forms (acquired outside the laboratory) can modify phoneme perception. For example, British English listeners who have moved to America learned to correctly interpret the medial flap in todal as /t/ (thereby recognizing the intended word total), but British listeners with little experience in General American found it difficult (Scott \& Cutler, 1984). Sumner and Samuel (2009) have further shown that listeners experienced with the New York City dialect recognize words with typical r-dropping more easily than inexperienced listeners do, and Sebastián-Gallés, Echeverría, and Bosch (2005) found that Catalan listeners who had experience with Spanish-accented Catalan easily recognized Spanishaccented *[gəКеðə] as the intended Catalan [gəКєðə] 'bucket', but treated atypical variants as nonwords. 
If long-term experience with a foreign accent influences word recognition in a comparable way, then we should find that experienced listeners recognize foreign-accented words more easily than inexperienced listeners. A further prediction is that, for experienced listeners, genuine accent markers should not hinder word recognition but arbitrary markers may do so. Experience with nonnative variants, however, differs from experience with native speech. First of all, the amount of experience with native variant forms usually outweighs the amount of experience with a foreign accent. Furthermore, listeners not only vary in how much exposure they have had to foreign accents, but also in how much experience with the target language they have. Furthermore, less proficient second language (L2) listeners are possibly not as efficient as first language (L1) listeners in using lexical knowledge (Bradlow \& Bent, 2008; Norris et al., 2003) to guide their interpretation of variant forms. Variant recognition could therefore be more difficult for L2 listeners than for L1 listeners.

But the degree of difficulty that an L2 listener might face with foreign-accented speech is likely to depend also on the combination of languages in question. We know from offline studies on the intelligibility of foreign accents that L1 listeners find L1 speech more intelligible than L2 speech, but L2 listeners can find L2 speech as intelligible as L1 speech, if the L2 in question is their native language (e.g., Bent \& Bradlow, 2003; van Wijngaarden, 2001). A native English listener and a nonnative Dutch listener could thus find native-accented English easier to understand than Italian-accented English, but a nonnative Italian listener could find the two speech forms equally easy. There are at least two reasons for such a difference between nonnative listeners. First, there is familiarity with the accent (Italian listeners are likely to have heard more Italian-accented English than Dutch listeners have). Second, the source of the difficulty with Italian-accented English for the Dutch (and English) listeners lies in properties of Italian - properties that may be beneficial for native Italian listeners. For instance, as we have already noted, the /I/-/i:/ contrast is not made in Italian. This creates problems for Italians when they speak English, but perhaps not when they are listening to Italian-accented English. If they cannot hear the difference between [I] and [i:], because these vowels are perceptually assimilated to a single high vowel category (Best, 1995), then they should find Eataly and Italy equally easy to recognize. Weber et al. (2011) have indeed shown comparable effects of perceptual confusability on word recognition by L2 listeners.

In Experiment 1, therefore, we compared monolingual native English listeners' ability to recognize Italian-accented English words containing /I/ and /i:/ with that of two nonnative listener groups: Italian-English bilinguals and Dutch-English bilinguals. Note that the three groups differed not only with respect to their native languages but also with respect to another aspect of their linguistic experience: The listeners in the two nonnative groups were bilinguals, capable of speaking more than one language proficiently, but the native listeners were effectively monolingual. Does becoming bilingual, including developing the ability to recognize multiple types of speech input, induce greater perceptual flexibility in lexical access? On the one hand, there are some indications that bilingualism can enhance cognitive flexibility (e.g., Bialystok, 2009; Bialystok \& Martin, 2004; but see Paap \& Greenberg, 2013), that bilinguals are flexible in speech production (Grosjean \& Miller, 1994), and that bilingual infants show greater flexibility in word learning than monolingual infants (Mattock, Polka, Rvachew, \& Krehm, 2010). On the other hand, bilinguals show no greater flexibility in speech perception than monolinguals, as indexed by the ability to discriminate the phonetic categories of an unknown language (Werker, 1986). It is thus not clear whether bilinguals will be able to adapt more readily to foreign-accented speech than monolinguals, but it is of course possible that bilinguals have enhanced flexibility in mapping a variable speech signal onto the mental lexicon even if they are no better than monolinguals in discriminating unknown speech sounds. We thus asked here if bilinguals are more flexible in word recognition than monolinguals. If they are, then this advantage should be observable in both languages of the bilinguals. Specifically, we asked if bilinguals could recognize foreign-accented words with an arbitrary accent marker more readily than monolinguals in both their second language (Experiment 1) and in their native language (Experiment 2).

\subsection{Design and predictions}

Experiment 1 used cross-modal identity priming to examine adaptation to words with genuinely and arbitrarily accented vowels in listeners with different types of prior linguistic experience. English words with either /I/ or /i:/ in their canonical pronunciation were selected as targets (e.g., trick or treat). An Italian speaker recorded all these words with canonical vowel length (/trik/, /tri:t/) and with mispronounced vowel length ( ${ }^{*} /$ tri:k/, */trit/). These recordings were used as primes. They were presented auditorily, and were followed immediately by printed targets, to which participants made lexical decisions. Mispronounced primes with /i:/ $\left({ }^{*} /\right.$ tri:k/) were genuine (i.e., typical of an Italian accent); those with /I/ ( ${ }^{*} / \mathrm{trt} /$ ) were arbitrary (i.e., atypical of an Italian accent). The design thus allowed a comparison of the recognition of words with genuinely and arbitrarily accented vowels, as well as a comparison of the recognition of words with accented and canonical vowels. The materials were presented to monolingual English $\mathrm{L} 1$ listeners (Experiment 1A), bilingual Italian-English L2 listeners (Experiment 1B), and bilingual Dutch-English L2 listeners (Experiment 1C).

The native English listeners in Experiment $1 \mathrm{~A}$ were familiar with the Italian accent, so facilitated recognition (i.e., faster responses to targets after related than after unrelated primes) was expected throughout the experiment for words with genuine Italian accent vowels (e.g., responses to trick faster after */tri:k/ than after an unrelated prime). If monolinguals are relatively inflexible listeners, treat pronounced with an arbitrarily-accented vowel (i.e., */trit/) should not facilitate recognition of treat, since although shortening of long vowels may be an accent marker for other foreign accents in English, it is not for Italian-accented English.

For the nonnative bilingual Italian listeners (Experiment 1B), */tri:k/ with an Italian accent vowel is certainly a familiar form and should therefore facilitate recognition throughout the experiment. Since Italian listeners cannot reliably distinguish between /I/ and /i:/ (this, after all, is one reason why they make errors in producing vowel length in the first place), */trit/ with an arbitrarily-accented vowel may also result in facilitatory priming for this group of listeners. 
Finally, the nonnative bilingual Dutch listeners in Experiment $1 \mathrm{C}$ were predicted to show a third pattern of performance. Dutch listeners can distinguish vowel length (Dutch makes the /I/-/i:/ contrast), and although they may not be very familiar with Italianaccented English, they are likely to have heard some Italian-accented Dutch. If these L1 experiences help with processing an Italian accent in L2, then Dutch L2 listeners should show priming for forms with genuinely-accented vowels such as */tri:k/. If, in addition, bilingual listeners are more perceptually flexible than monolingual listeners, the bilingual Dutch participants could (unlike the monolingual native English participants) also show priming for forms with arbitrarily-accented vowels such as */trit/.

\section{Experiment $1 \mathrm{~A}$}

\subsection{Method}

\subsubsection{Participants}

Forty-eight native listeners of English were paid to take part. All participants were students at the University of Sheffield, and had no reported reading or hearing disabilities. Although most of the participants reported having studied two foreign languages in school, only six stated that they could understand a second language. The foreign languages were mostly French and German and participants started learning them at school at the age of 11, for on average 4 years. Only one of the participants knew some Italian. None were proficient in a second language. The listeners, as a group, were thus effectively monolingual. Half of the participants listened to an experimental version in which all experimental prime words contained the long vowel /i:/ (the genuine accent vowel condition), and the other half listened to a version in which all experimental prime words contained the short vowel /I/ (the arbitrary accent vowel condition).

\subsubsection{Materials}

Forty mono- and bisyllabic English words with the short vowel /I/ (e.g., trick) and 40 words with the long vowel /i:/ (e.g., treat) were chosen as visual target words. Each target was combined with three auditory prime words: a prime with correct vowel length, a prime with incorrect vowel length, and an unrelated prime. The first prime type was the standard pronunciation of the vowel in the target, the second prime type had lengthened vowels in targets with short /I/ and shortened vowels in targets with long /i:/, and the third prime type was a word that was phonologically and semantically unrelated to the target (e.g., store for target trick, and odd for target treat). When the vowel in targets with short /I/ was lengthened (e.g., trick pronounced as */tri:k/), the resulting variant form was typical of an Italian accent in English (genuine vowel primes), but when the vowel in targets with long /i:/ was shortened (e.g., treat pronounced as */trit/), the resulting variant was not typical of an Italian accent in English (arbitrary vowel primes). The variant forms never formed existing English words but were always phonotactically legal. All critical items are listed in Appendix A.

An additional 80 English words containing no /i:/ or /I/ were chosen as filler target words. Twenty of these fillers were paired with primes that were the correct pronunciations of those words (e.g., target bribe and prime bribe), 20 more were paired with primes that formed minimal pairs with the filler target words (e.g., target battle and prime bottle), and the remaining 40 filler target words were paired with unrelated primes. In order to have an equal number of yes and no responses in the lexical decision task, 160 English nonwords were chosen as filler nonword targets. Again, the nonword filler targets never contained /i:/ or / I/. Nonword filler targets were always paired with English prime words that either differed in one phoneme from the nonwords (e.g., target barth and prime birth; 80 pairs) or were totally unrelated (e.g., target brang and prime ghost; 80 pairs). Furthermore, 12 representative target-prime pairs were selected as practice items.

A female native Italian (the second author), who had been living in England for 11 years, was the speaker of the experimental stimuli; she was highly proficient in English, with a mild to moderate accent in her pronunciation. That is, the Italian background of our speaker was perceptible on a good number of segments in her speech. She recorded all related target primes both with the correct vowel length and with the incorrect vowel length, all unrelated target primes, and all filler and practice primes in one session. A native speaker of English (the third author) was present during the recording session and checked that the speaker produced the vowels as intended. Multiple tokens were recorded for each item and the best recording of each word was later selected. Acoustical analyses using Praat (Boersma, 2001) showed that the vowel in words with short /I/ (e.g., trick) was on average $161 \mathrm{~ms}$ shorter in the canonical vowel forms than in the variant vowel forms, while the vowel in words with long /i:/ (e.g., treat) was on average $131 \mathrm{~ms}$ longer in the canonical vowel forms than in the variant vowel forms. Likewise, the first three formants at the vowel midpoint differed reliably for canonical and variants vowel forms, with $F 1$ being lower in long vowels than in short vowels, and both $F 2$ and $F 3$ being higher for long vowels than for short vowels (see Table 1 for values and statistical analyses of the female speaker in Experiment 1 ). Marking the difference between /i:/ and /I/ not just in duration but also spectrally is indeed standard for the English vowel contrast (e.g., Flege \& Bohn, 1997), and the fact that the Italian speaker reliably produced both differences speaks for her proficiency in English. To facilitate comparison, we provide in Table 2 average $F 1$ and $F 2$ values for American English and Italian /i/ vowels (collapsed over male and female speakers) as they are reported in Strange et al. (2007) and Ferrero, Magno Caldognetto, Vagges, and Lavagnoli (1978) respectively.

It was decided not to present a mix of primes with short and long vowels to individual participants; listeners would then encounter correct and incorrect pronunciations of a vowel from the same speaker, which could negatively affect short-term adaptation (see Kraljic, Samuel, \& Brennan, 2008). This meant that genuine vs. arbitrary accent marker was a between-participant factor. Two versions of the experiment were constructed, one in which all related primes contained long vowels (e.g., /tri:t/ and */tri:k/; genuine Italian accent vowel) and one in which all related primes contained short vowels (e.g., */trit/ and /trik/; arbitrary accent vowel). Each version included all 80 experimental targets presented either with a related or unrelated prime, with items counterbalanced across versions. In the 
Table 1

Average durations (in $\mathrm{ms}$ ) and formant values (in $\mathrm{Hz}$ ) at vowel midpoint for canonical and variant vowel forms in Experiment 1.

\begin{tabular}{|c|c|c|c|}
\hline & Canonical vowel form & Variant vowel form & Paired $t$-test \\
\hline \multicolumn{4}{|c|}{ /I/ words, e.g., trick } \\
\hline Duration & 88 & 250 & $t(39)=-19.72^{\text {***** }}$ \\
\hline$F 1$ & 474 & 396 & $t(39)=8.70^{* * *}$ \\
\hline$F 2$ & 2340 & 2843 & $t(39)=-15.28^{* * *}$ \\
\hline$F 3$ & 2897 & 3740 & $t(39)=-14.40^{\text {**** } * *}$ \\
\hline \multicolumn{4}{|c|}{ /i:/ words, e.g., treat } \\
\hline Duration & 238 & 108 & $t(39)=16.42^{* * *}$ \\
\hline$F 1$ & 383 & 457 & $t(39)=-10.39^{* * *}$ \\
\hline$F 2$ & 2863 & 2422 & $t(39)=12.02^{* * *}$ \\
\hline$F 3$ & 3821 & 3006 & $t(39)=16.14^{* * *}$ \\
\hline
\end{tabular}

*** $p<.001$.

Table 2

Average $F 1$ and $F 2$ values (in $\mathrm{Hz}$ ) for American English and Italian from Strange et al. (2007) and Ferrero et al. (1978).

\begin{tabular}{lcr}
\hline & American English & Italian \\
\hline II/ & & \\
F1 & 516 & \\
F2 & 1958 & \\
li/ & & 290 \\
$F 1$ & 293 & 2310 \\
F2 & 2458 & \\
\hline
\end{tabular}

Table 3

Average RTs (in ms) and error rates and standard deviation of error rates (in brackets) for monolingual English L1 listeners in Experiment $1 \mathrm{~A}$.

\begin{tabular}{|c|c|c|c|c|}
\hline & \multicolumn{2}{|c|}{ Genuine Italian accent vowel } & \multicolumn{2}{|c|}{ Arbitrary accent vowel } \\
\hline & Canonical /tri:t/ & Variant ${ }^{*} /$ tri:k/ & Canonical /trik/ & Variant $*$ trit/ \\
\hline Related primes & $583(1.0 \%, 2.07)$ & $618(0.6 \%, 1.68)$ & $574(1.0 \%, 2.54)$ & $661(1.9 \%, 3.55)$ \\
\hline Unrelated primes & $685(2.3 \%, 3.29)$ & $663(1.7 \%, 2.82)$ & $662(1.5 \%, 2.32)$ & $676(1.9 \%, 3.55)$ \\
\hline
\end{tabular}

genuine accent vowel version, 20 target words with short /I/ (e.g., trick) were presented with their Italian-accented vowel primes (e.g., */tri:k/) and 20 with their unrelated primes, and 20 target words with long /i:/ (e.g., treat) were presented with their canonical (and accentappropriate) vowel primes (e.g., /tri:t/) and 20 with their unrelated primes. In the arbitrary accent vowel version, 20 target words with long /i:/ were presented with their arbitrarily-accented vowel primes (e.g., */trit/) and 20 with their unrelated primes, and 20 target words with short /I/ were presented with their canonical vowel primes (e.g., /trIk/) and 20 with their unrelated primes.

For the two versions, four lists were created to allow each target to be presented once in every condition. Each list began with the practice trials, and further contained all 80 experimental and 240 filler trials; before each experimental trial there was at least one filler trial. Each list was presented to an equal number of participants, with the order of trial presentations being different for each participant.

\subsubsection{Procedure}

Participants were tested one at a time in a quiet room. At the beginning of a session, they received instructions in English informing them that they would hear an English word, directly after which a real English word or a nonword would appear on the computer screen in front of them. They were asked to press with their dominant hand a response key labeled "yes" if they thought the word on the screen was a real English word, and to press with their non-dominant hand a response key labeled "no" if they thought it was not an existing English word. Participants were asked to respond both as fast and as accurately as possible. After the practice trials, participants could ask questions before the experiment started.

The experiment was controlled with DMDX software (Forster \& Forster, 2003). Auditory stimuli were presented binaurally over closed headphones, and at their offset the visual stimulus was presented on the computer screen. Reaction times (RTs) were measured from the onset of the presentation of the visual stimuli. Participants had $3000 \mathrm{~ms}$ to respond, and $1000 \mathrm{~ms}$ after a key response the following auditory stimulus was played.

\subsection{Results and discussion}

Correct responses to targets with RTs shorter than $200 \mathrm{~ms}$ and longer than 2000 ms were considered as outliers and were removed from all subsequent analyses (a total of 11 responses longer than $2000 \mathrm{~ms}, 0.3 \%$ of all experimental trials). The remaining 


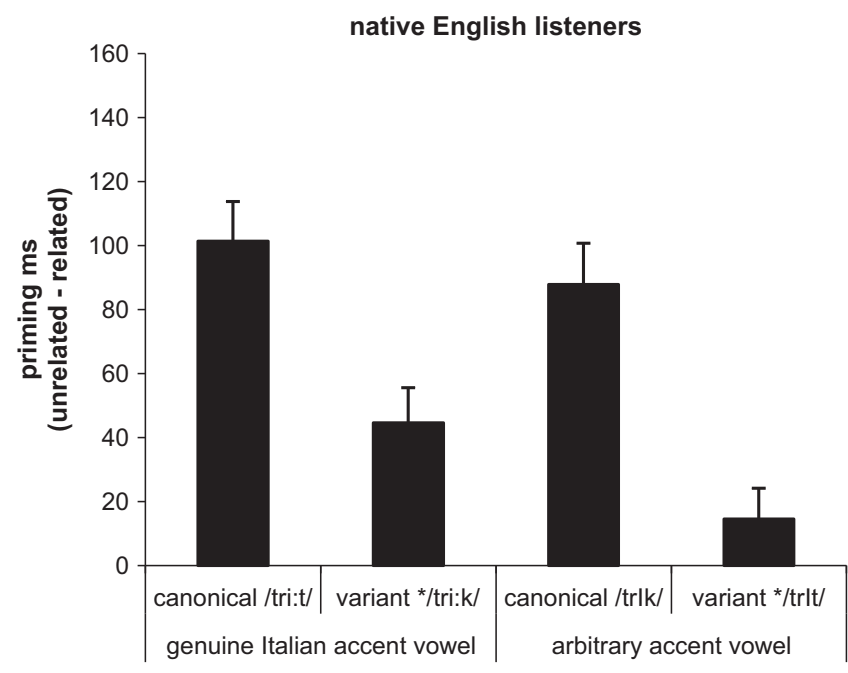

Fig. 1. Priming effects in ms for monolingual English L1 listeners in Experiment $1 \mathrm{~A}$. Error bars represent standard error of the mean.

correct RTs and error rates for each condition are presented in Table 3. The native English participants in Experiment $1 \mathrm{~A}$ made very few errors, so error rates are not analyzed statistically. Calculated priming effects for the RTs (i.e., the difference in RTs to targets following unrelated and related primes) for each condition are shown in Fig. 1.

RTs were submitted to Analyses of Variance (ANOVAs) to examine the effects of version (with the two levels genuine and arbitrary), prime form (with the two levels canonical and variant), and relatedness (with the two levels related and unrelated). Prime form and relatedness were within-participants and within-items factors, and version was between-participants and between-items.

Overall ANOVAs on RTs showed main effects of prime form $\left(F_{1}[1,46]=16.82, p<.001 ; F_{2}[1,78]=16.00, p<.001\right)$, and relatedness $\left(F_{1}[1,46]=99.65, p<.001 ; F_{2}[1,78]=78.39, p<.001\right)$, as well as interactions between prime form and version $\left(F_{1}[1,46]=10.19\right.$, $\left.p<.01 ; F_{2}[1,78]=9.46, p<.01\right)$, prime form and relatedness $\left(F_{1}[1,46]=37.41, p<.001 ; F_{2}[1,78]=17.57, p<.001\right)$, and a weak interaction between relatedness and version $\left(F_{1}[1,46]=3.05, p>.08 ; F_{2}<1\right)$. No other interactions were significant.

To further explore the interactions in the RT analyses, separate analyses for prime forms with canonical and variant vowels were conducted. For canonical vowel forms, there was a main effect of relatedness $\left(F_{1}[1,46]=111.524, p<.001 ; F_{2}[1,78]=47.86\right.$, $p<.001)$, with RTs being overall faster after canonical vowel primes than after unrelated primes, and no interaction between relatedness and version $\left(F_{1}\right.$ and $\left.F_{2}<1\right)$. Thus, not surprisingly, there was comparable facilitatory priming for English listeners when they were presented with English words with long and short vowels, such as trick and treat, being pronounced canonically.

For variant vowel forms, statistical analyses showed a main effect of relatedness $\left(F_{1}[1,46]=16.50, p<.001 ; F_{2}[1,78]=9.86\right.$, $p<.01)$, as well as a significant interaction by participants between relatedness and version $\left(F_{1}[1,46]=4.21, p<.05 ; F_{2}<1\right)$. Subsequent paired $t$-tests showed a facilitatory priming effect for the Italian-accented variant form (i.e., faster RTs to trick after the Italian-accented prime $* /$ tri:k/ than after the unrelated prime; $\left.t_{1}[1,23]=16.38, p<.001 ; t_{2}[1,39]=5.57, p<.05\right)$. Arbitrarily-accented variant forms, however, did not cause facilitatory priming (i.e., RTs were comparable to treat after */trit/ and after the unrelated prime; $\left.t_{1}[1,23]=2.31, p>.1 ; t_{2}[1,39]=1.61, p>.2\right)$. This suggests that English listeners could easily recognize words with vowel lengthening, which is a typical characteristic of an Italian accent, but the same was not true in the case of atypical vowel shortening. A likely reason for English listeners being able to interpret */tri:k/ as trick but not */trit/ as treat is familiarity with the Italian accent. There are a considerable number of residents in the United Kingdom with Italian as the first language, and many Italian tourists visit England regularly. It can be therefore assumed that English listeners are acquainted with the Italian accent and this familiarity with the accent prevents them from treating vowel shortening such as */trit/ for treat as a genuine accent marker of Italian speakers of English. In fact, when participants were asked after the priming experiment if they could identify the accent of the speaker, Italian and Spanish were the answers that were given the most. Specifically, 35\% of the native English participants recognized the speaker as Italian, and overall $46 \%$ of them thought the speaker was either Italian or Spanish (note that Spanish, like Italian, does not make the /i:-I/ contrast, so Spaniards, like Italians, also tend to say /tri:k/ for trick; e.g., Coe, 2001).

Even though Italian-accented */tri:k/ primed the recognition of trick, further analyses showed that this effect was not as strong as the comparable effect for the canonical pronunciation of trick. That is, there was a significant interaction between relatedness and prime form in a between-participants analysis comparing priming from the canonical forms of words with /i:/ with the genuine-accent variant forms of the same words $\left(F_{1}[1,46]=6.51, p<.01 ; F_{2}[1,78]=3.78, p<.05\right)$. Not surprisingly, for native listeners of English, the canonical pronunciation of trick was recognized more easily than the Italian-accented form.

\section{Experiment 1B}

In Experiment 1B, we tested the ability of Italian L2 listeners to interpret correctly the canonical and variant vowel forms that had been used in Experiment $1 \mathrm{~A}$. In contrast to listening to your native language, L2 listening is usually more difficult. While parts of this difficulty can be linked to a smaller vocabulary in the L2, to lexical competition from the L1 (Weber \& Cutler, 2004), and to less 
experience with hearing and speaking the $L 2$, previous research has shown that $L 2$ perception is in certain cases just not as flexible as L1 perception is. For example, even after years of experience, certain L2 sound contrasts can remain difficult to distinguish (Bohn \& Munro, 2007), and compensating for phonological variation in L2 can take longer for L2 listeners than for L1 listeners (Darcy, Peperkamp, \& Dupoux, 2007). L2 listeners thus appear to be less efficient in adapting to the pronunciation of a particular speaker, and at the same time their perceptual difficulties can influence their word recognition abilities perhaps even permanently. However, when someone listens to an L2 spoken by a nonnative who speaks the same L1 (e.g., an Italian listening to Italian-accented English) these difficulties may be diminished (e.g., Bent \& Bradlow, 2003). Italian listeners are of course highly familiar with their own accent, and this could allow them to interpret Italian-accented variant forms correctly. Furthermore, because Italian listeners have difficulties distinguishing vowel length in English, it is possible that they will even be able to recognize forms with unfamiliar, arbitrarily-accented vowels correctly (because they may not hear the difference between variant and canonical vowel forms). There may therefore be priming for both genuine and arbitrary variants for this group of listeners.

\subsection{Method}

\subsubsection{Participants}

Thirty-two proficient Italian learners of English participated for a small monetary compensation. Most participants were students at the University of Sheffield, and none of them reported reading or hearing disabilities. They had all started learning English during their childhood (mean age $=11$ years) and studied it on average for 9 years. They reported that they had been living in an Englishspeaking country for 22 months on average. Eleven of them had learned at least one other foreign language in school (typically French or German) for an average of 4 years. Half of the participants listened to the experimental version with prime words containing the long vowel /i:/ (the genuine accent vowel condition), and the other half listened to the version with prime words containing the short vowel /I/ (the arbitrary accent vowel condition).

\subsubsection{Materials and procedure}

These were the same as in Experiment $1 \mathrm{~A}$.

\subsection{Results and discussion}

The data from one participant in the genuine accent vowel condition had to be excluded due to technical problems. Furthermore, 24 responses with RTs shorter than 200 ms or longer than $2000 \mathrm{~ms}$ ( $1 \%$ of all experimental trials) were considered as outliers and were removed from the following analyses. RTs for the remaining correct responses and error rates are reported in Table 4, and the corresponding priming effects for RTs are shown in Fig. 2. Correct RTs and error rates were submitted to ANOVAs comparable to those in Experiment 1.

Table 4

Average RTs (in ms) and error rates and standard deviation of error rates (in brackets) for bilingual Italian-English L2 listeners in Experiment 1B.

\begin{tabular}{|c|c|c|c|c|}
\hline & \multicolumn{2}{|c|}{ Genuine Italian accent vowel } & \multicolumn{2}{|c|}{ Arbitrary accent vowel } \\
\hline & Canonical /tri:t/ & Variant $*$ tri:k/ & Canonical /tri:k/ & Variant $*$ trit/ \\
\hline Related primes & $647(3.7 \%, 4.41)$ & $700(4.6 \%, 7.03)$ & $665(6.3 \%, 8.26)$ & $712(11.6 \%, 8.89)$ \\
\hline Unrelated primes & $768(8.6 \%, 10.13)$ & $783(6.4 \%, 9.48)$ & $800(9.7 \%, 7.41)$ & $783(12.8 \%, 10.32)$ \\
\hline
\end{tabular}

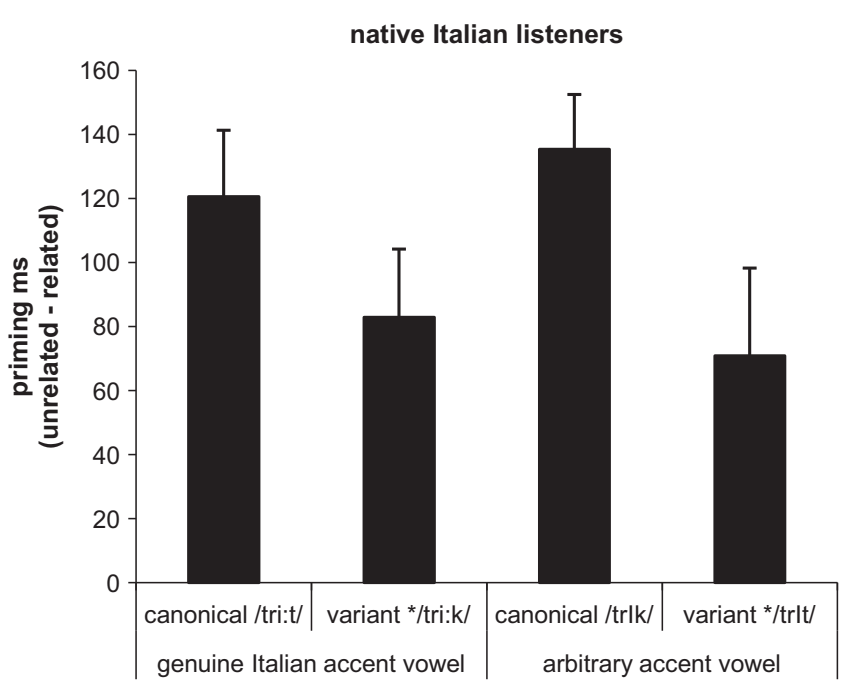

Fig. 2. Priming effects in ms for bilingual Italian-English L2 listeners in Experiment 1B. Error bars represent standard error of the mean. 
As for the English listeners in Experiment 1A, the overall ANOVAs on RTs in Experiment 1B showed main effects of prime form by participants $\left(F_{1}[1,29]=12.32, p<.001 ; F_{2}[1,78]=1.05, p<.3\right)$, and of relatedness $\left(F_{1}[1,29]=62.86, p<.001 ; F_{2}[1,78]=37.79\right.$, $p<.001)$, as well as an interaction between prime form and relatedness $\left(F_{1}[1,29]=8.42, p<.01 ; F_{2}[1,78]=7.87, p<.01\right)$. No other interactions were significant.

Even though the Italian L2 listeners made more errors than the English L1 listeners, error rates were overall still quite low $(7.9 \%$ on average), which attests to the proficiency of the Italian participants in English. ANOVAs on error rates revealed a main effect of relatedness $\left(F_{1}[1,29]=3.72, p>.06 ; F_{2}[1,29]=6.35, p<.02\right)$ with fewer errors produced on targets with a related prime than with an unrelated prime, as well as an interaction by participants between prime form and version $\left(F_{1}[1,29]=6.47, p<.02 ; F_{2}<1\right)$ that was driven by a higher rate of errors for targets with variant primes containing a short vowel. Due to the generally quite low error rate, the errors will not be analyzed further.

Separate RT analyses for the two prime forms revealed main effects of relatedness for both canonical $\left(F_{1}[1,29]=90.92, p<.001\right.$; $\left.F_{2}[1,78]=79.52, p<.001\right)$ and variant vowel forms $\left(F_{1}[1,29]=19.13, p<.001 ; F_{2}[1,78]=4.06, p<.05\right)$, but no interactions involving relatedness and version (for canonical vowel forms: $F_{1} \& F_{2}<1$; for variant vowel forms: $F_{1}$ and $F_{2}<1$ ). That is, RTs following canonical vowel primes and RTs following variant vowel primes were both faster than RTs following unrelated primes, and this facilitatory priming effect was found for target words with /i:/ and /I/ alike.

Facilitatory priming for both the variant form with an Italian accent vowel */tri:k/ and the variant form with an arbitrarily-accented vowel */trit/ in Experiment 1B speaks for an influence of perceptual difficulties on English word recognition by Italian L2 listeners. Priming for variant forms that are typical of an Italian accent could in principle reflect prior linguistic experience of Italian listeners with their own accent. Italian listeners have certainly been exposed to Italian-accented English before, either in their own L2 productions or in those of their fellow countrymen, and through this exposure they could have learned how to interpret Italian-accented words in English correctly. However, in the case of variant forms with arbitrarily-accented vowels, Italian listeners could not have assembled experience in the same way, but facilitatory priming was found for these variant forms nevertheless. Italian listeners not only have difficulties producing a contrast in vowel length but also perceiving it (Flege, MacKay, \& Meador, 1999). This inability to reliably distinguish vowel length allowed priming of variants that are not typical of the listeners' own accent but that are perceptually confusable with the canonical vowel form.

The direct comparison of priming effects for canonical forms and variant forms (between participants) also provides support for this perceptual confusability account. While for English listeners in Experiment $1 \mathrm{~A}$ canonical forms always primed more strongly than variant forms, for Italian listeners in Experiment 1B there was no significant advantage for canonical forms over genuinely accented variant forms (i.e., the interaction between relatedness and prime form was not significant; $\left(F_{1}[1,29]=2.04, p>.1 ; F_{2}[1,78]=1.78\right.$, $p>$.1). For the arbitrarily accented variant forms, the advantage of canonical forms was also not significant $\left(F_{1}[1,29]=3.70, p>.05\right.$; $\left.F_{2}[1,78]=1.98, p>.1\right)$.

\section{Experiment $1 \mathrm{C}$}

If the Italian results indeed reflect in part perceptual difficulties with distinguishing vowel length, and not a general difference between how L1 and L2 listeners handle variation in speech, then L2 listeners who can distinguish vowel length should show a different pattern of results. Dutch learners of English are such a group of listeners, since vowel length is contrastive in Dutch (e.g., van der Feest \& Swingley, 2011). As with native listeners, therefore, Dutch listeners should have no difficulties perceiving the mispronunciations. Dutch listeners should also be familiar with the Italian accent, although for them the experience will stem mostly from Italian-accented Dutch and not from Italian-accented English. If it is sufficient to have experience with the Italian lengthening of short vowels in general rather than being familiar with the Italian accent in the language of the experiment, then we should find that for Dutch listeners, like the English listeners in Experiment 1A, primes with Italian-accented vowels facilitate word recognition. Furthermore, if becoming a proficient bilingual enhances perceptual flexibility, then the Dutch L2 listeners may also show priming from primes with arbitrarily-accented vowels (unlike the monolingual native listeners in Experiment $1 \mathrm{~A}$, and like the bilingual Italian listeners in Experiment 1B, but for a different reason).

\subsection{Method}

\subsubsection{Participants}

Forty-eight native Dutch listeners proficient in English participated for a small monetary compensation. All participants were students at the Radboud University Nijmegen and were tested at the Max Planck Institute for Psycholinguistics in Nijmegen, the Netherlands. The Dutch listeners had started learning English at the age of 11 years on average, had studied it for 7.5 years on average, and were proficient in English. All participants had also studied a third and a fourth language at school (typically German and French) for 5 years on average; only two had studied Italian for one year. Half of the participants were assigned to the genuine accent condition and half to the arbitrary accent condition.

\subsubsection{Materials and procedure}

These were the same as before. 


\subsection{Results and discussion}

The two items gleam and canteen were taken out of the analyses because the majority of participants made errors on them. Furthermore, 32 responses with RTs shorter than $200 \mathrm{~ms}$ or longer than $2000 \mathrm{~ms}(0.8 \%$ of all experimental trials) were considered as outliers and have been removed from the following analyses. RTs for correct responses and error rates are reported in Table 5; corresponding priming effects for RTs are shown in Fig. 3. Correct RTs and error rates were again submitted to ANOVAs like those performed in the earlier experiments.

For Dutch L2 listeners, the RT analyses revealed main effects of prime form by participants $\left(F_{1}[1,46]=8.76, p<.01 ; F_{2}<1\right)$ and of relatedness $\left(F_{1}[1,46]=49.33, p<.001 ; F_{2}[1,76]=75.85, p<.001\right)$. There was furthermore a significant interaction between prime form and relatedness $\left(F_{1}[1,46]=41.27, p<.001 ; F_{2}[1,76]=25.16, p<.001\right)$. No other interactions were significant.

Average error rates of Dutch L2 listeners in Experiment $1 \mathrm{C}(9.6 \%)$ were comparable to error rates of Italian L2 listeners in Experiment 1B, showing that the Dutch listeners had no substantial problems performing the task in their L2. ANOVAs on error rates in Experiment $1 \mathrm{C}$ revealed no main effect of prime form, but a main effect of relatedness $\left(F_{1}[1,46]=5.13, p<.05 ; F_{2}[1,76]=3.07\right.$, $p>.05$ ) with fewer errors being made to targets following related primes than unrelated primes and an interaction between prime form and version $\left(F_{1}[1,46]=16.59, p=.001 ; F_{2}[1,76]=11.27, p<.001\right)$. The errors will not be analyzed further.

As in Experiments $1 \mathrm{~A}$ and 1B, ANOVAs on RTs were run separately for canonical vowel forms and variant vowel forms, with relatedness as within-subject factor and version as a between-subject factor. For canonical vowel forms, there was a main effect of relatedness $\left(F_{1}[1,46]=84.16, p<.001 ; F_{2}[1,76]=98.24, p<.001\right)$, but no effect of version $\left(F_{1}\right.$ and $\left.F_{2}<1\right)$ and no interaction between relatedness and version $\left(F_{1}<1 ; F_{2}[1,76]=2.203, p>.1\right)$. Thus, as for English L1 listeners and Italian L2 listeners, there was facilitatory priming for Dutch L2 listeners when they were presented with the canonical vowel forms of English words with long and short vowels such as trick and treat.

For the variant vowel forms in Experiment $1 C$, there was a significant effect of relatedness $\left(F_{1}[1,46]=4.63, p<.05 ; F_{2}[1,76]=\right.$ $5.47, p<.05)$ and no interaction between relatedness and version $\left(F_{1}\right.$ and $\left.F_{2}<1\right)$. Thus, in contrast to English L1 listeners in Experiment $1 \mathrm{~A}$, Dutch $\mathrm{L} 2$ listeners showed priming for variant vowel forms, regardless of whether they were genuinely accented as in */tri:k/ or arbitrarily accented as in */trit/.

The comparison between versions showed that canonical primes always resulted in stronger facilitatory effects than variant primes: that is, the interaction between relatedness and prime form was significant both when Italian variants were compared to their canonical counterparts $\left(F_{1}[1,46]=23.56, p<.001 ; F_{2}[1,76]=17.13, p<.001\right)$ and when arbitrary variants were compared to their canonical counterparts $\left(F_{1}[1,46]=21.33, p<.001 ; F_{2}[1,78]=8.35, p<.01\right)$.

Table 5

Average RTs (in ms) and error rates and standard deviation of error rates (in brackets) for bilingual Dutch-English L2 Listeners in Experiment 1C.

\begin{tabular}{|c|c|c|c|c|}
\hline & \multicolumn{2}{|c|}{ Genuine Italian accent vowel } & \multicolumn{2}{|c|}{ Arbitrary accent vowel } \\
\hline & Canonical /tri:t/ & Variant $* /$ tri:k/ & Canonical /trik/ & Variant $*$ trit $/$ \\
\hline Related primes & $622(10.6 \%, 8.38)$ & $685(7.7 \%, 7.65)$ & $638(5.4 \%, 7.35)$ & $690(10.4 \%, 8.19)$ \\
\hline Unrelated primes & $733(12.9 \%, 9.19)$ & $706(9.8 \%, 12.37)$ & $729(8.8 \%, 8.50)$ & $724(11.3 \%, 6.29)$ \\
\hline
\end{tabular}

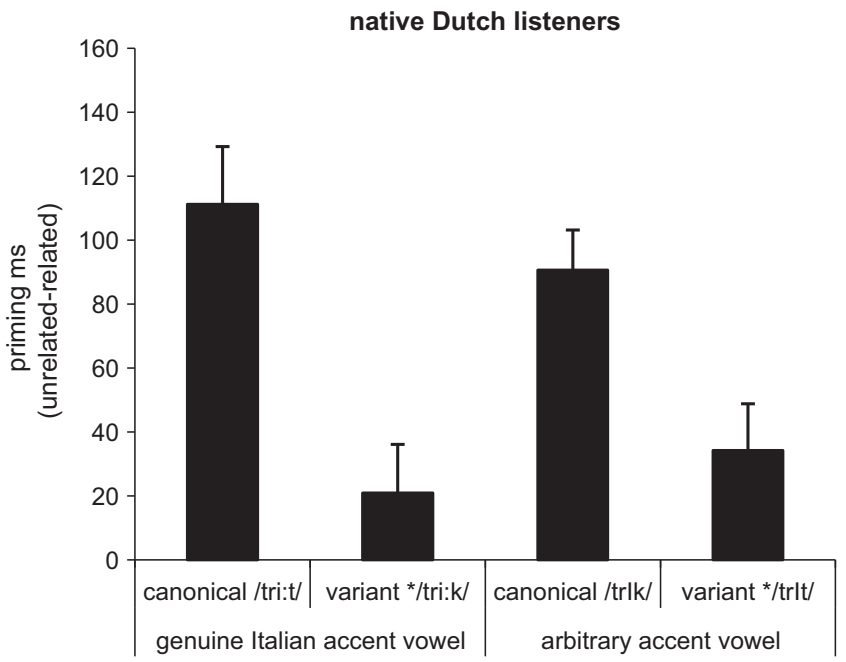

Fig. 3. Priming effects in $\mathrm{ms}$ for bilingual Dutch-English L2 listeners in Experiment 1C. Error bars represent standard error of the mean 


\subsection{Cross-listener and cross-version analyses}

A comparison of the results across all three listeners groups (Experiments $1 \mathrm{~A}, 1 \mathrm{~B}$, and $1 \mathrm{C}$ ) was carried out to confirm that there was an effect of language background on the processing of variant forms. There were effects of prime form $\left(F_{1}[1,121]=34.26, p<.001\right.$, $\left.F_{2}[1,232]=4.90, p<.02\right)$, relatedness $\left(F_{1}[1,121]=203.82, p<.001, F_{2}[1,232]=149.90, p<.001\right)$, and group $\left(F_{1}[1,121]=8.31, p<.001\right.$, $\left.F_{2}[2,232]=30.49, p<.001\right)$, as well as an interaction between relatedness and group significant by participants $\left(F_{1}[1,121]=5.24, p<.01\right.$, $\left.F_{2}[2,232]=1.92, p>.1\right)$, an interaction between prime form and relatedness $\left(F_{1}[1,121]=72.00, p<.001, F_{2}[1,232]=39.30, p<.001\right)$, and between prime form, version, and group $\left(F_{1}[1,121]=4.8, p=.01, F_{2}[1,232]=3.02, p>.05\right)$. Pairwise comparisons between groups revealed three-way interactions involving prime form, group, and version for the comparison of English L1 listeners versus Italian $\mathrm{L} 2$ listeners $\left(F_{1}[1,75]=9.56, p<.01, F_{2}[1,156]=3.41, p<.01\right)$, for the comparison of English $L 1$ listeners versus Dutch $L 2$ listeners $\left(F_{1}[1,92]=\right.$ $\left.3.27, p<.06, F_{2}[1,156]=5.85, p<.05\right)$, but not for Italian L2 listeners versus Dutch L2 listeners $\left(F_{1}[1,75]=1.90, p>.1, F_{2}<1\right)$. These group comparisons confirm that English L1 listeners behaved differently from both Italian L2 listeners and Dutch L2 listeners.

To further investigate whether the observed priming effects for variant vowel forms in Experiment 1 were equivalent to those of canonical vowel forms, comparisons across versions were carried out for the three listener groups. For English listeners in Experiment $1 \mathrm{~A}$, canonical vowel forms were always recognized more easily than variant vowel forms, that is, the interaction between relatedness and prime form was significant, both when canonical /trik/ was compared to Italian-accented */tri:k/ $\left(F_{1}[1,46]=6.51\right.$, $\left.p<.01 ; F_{2}[1,78]=3.78, p<.05\right)$ and when canonical /tri:t/ was compared to arbitrarily-accented */trak/ $\left(F_{1}[1,46]=15.84, p<.001\right.$; $\left.F_{2}[1,78]=6.12, p<.01\right)$. For Italian listeners in Experiment $1 \mathrm{~B}$, there was neither a significant advantage for canonical forms over genuinely accented variant forms $\left(F_{1}[1,29]=2.04, p>.1 ; F_{2}[1,78]=1.78, p>.1\right)$ nor for the arbitrarily accented variant forms $\left(F_{1}[1,29]=3.70, p>.05 ; F_{2}[1,78]=1.98, p>.1\right)$. For Dutch listeners in Experiment $1 \mathrm{C}$, canonical primes always resulted in stronger priming than variant primes both for genuinely accented variant forms $\left(F_{1}[1,46]=23.56, p<.001 ; F_{2}[1,76]=17.13, p<.001\right)$ and for arbitrarily accented variant forms $\left(F_{1}[1,46]=21.33, p<.001 ; F_{2}[1,78]=8.35, p<.01\right)$.

\section{Experiment 2}

Experiment 1 suggests that accommodation to genuine pronunciations of words in foreign-accented speech is pervasive. It was found for monolingual native listeners (Experiment $1 \mathrm{~A}$ ) and for two groups of bilingual non-native listeners, both those who were native speakers of the same language as the speaker of the experimental materials (Experiment 1B) and those who had a different native language (Experiment $1 \mathrm{C}$ ). Adaptation to foreign-accented speech is thus possible in a second language.

Experiment 1 also suggests that nonnative listeners but not native listeners can interpret words with arbitrary accent markers. We have suggested that the reason why the Italian nonnative listeners showed priming for words with arbitrarily-accented vowels is based on perceptual confusability (inability to discriminate between the genuine and arbitrary variants). We have also suggested that the Dutch nonnative listeners showed priming for words with arbitrarily-accented vowels because, as bilinguals, they have greater perceptual flexibility than monolingual listeners. All of the Dutch participants in Experiment $1 \mathrm{C}$, like the Dutch student population in general, were bilinguals who speak Dutch natively and English proficiently and who also had some ability in other languages. All Dutch children also receive a great deal of experience from an early age with English, through films, television and music (e.g., films in the Netherlands are subtitled, not dubbed). In contrast, the English listeners in Experiment $1 \mathrm{~A}$ were effectively monolingual (i.e., they were not fluent in any other language) and had much more limited experience with listening to foreign languages. More extensive life-long experience with multiple languages could make it easier for listeners to adapt to variation in speech, including arbitrary forms of foreign-accented speech.

There is an alternative explanation for the results with arbitrarily-accented vowels, however. This is simply that the English listeners, who were performing the task in their native language and hence had had more experience with Italian-accented English than the Dutch listeners, may have had more detailed knowledge about the accent than the Dutch. The English listeners could have learned that vowel lengthening is a feature of Italian-accented English, and that vowel shortening is not, and hence were willing to accept only the words with lengthened vowels as variant pronunciations.

Two hypotheses were therefore tested in Experiment 2: are the differences between the English and Dutch listeners in Experiment 1 (only the latter group showing adaptation to forms with arbitrarily-accented vowels) because the former group, as native speakers, know more about what counts as a genuine Italian accent or because the latter group have greater perceptual flexibility, arising from their multilingual experience? Dutch listeners performed a cross-modal priming task that was comparable in design to that in Experiment 1, but now in their native language Dutch. On the one hand, if there is indeed a difference between adaptation in L1 and in L2 because only L1 listeners are sensitive to the genuineness of an accent, then we should find that Dutch L1 listeners in Experiment 2 behave like the English L1 listeners in Experiment 1A, that is, they should not adapt to primes with arbitrarily-accented vowels. On the other hand, if the multilingual experience of Dutch listeners drives their readiness to adapt, then Dutch listeners in Experiment 2 should adapt both to primes with genuine Italian-accented vowels and to primes with arbitrarily-accented vowels just as equivalent individuals did, as L2 listeners, in Experiment $1 \mathrm{C}$.

\subsection{Method}

\subsubsection{Participants}

Thirty-two native listeners of Dutch participated in Experiment 2 for a small monetary compensation. All participants were students at the Radboud University in Nijmegen, and had no reported reading or hearing disabilities. They were drawn from the same 
population as that used in Experiment $1 \mathrm{C}$ (though none of them had taken part in the earlier study). As in Experiment 1C, all participants were proficient in English, but also had studied a third and a fourth language at school. None had studied Italian. Half of the participants listened to an experimental version with genuine Italian-accented Dutch words (i.e., primes containing the long vowel /i:/), and the other half listened to a version with arbitrarily accented prime words (containing the short vowel /I/).

\subsubsection{Materials}

The Dutch materials were modeled on the English materials in Experiment 1. That is, 40 Dutch words with short vowel /I/ (e.g., prins 'prince') and 40 words with long vowel /i:/ (e.g., brief 'letter') were chosen as visual target words. Each visual target word was combined with a prime with correct vowel length, a prime where the vowel in the words with short /I/ was lengthened or the vowel in words with long /i:/ was shortened, and a phonologically and semantically unrelated prime. When the vowel was lengthened (e.g., prins pronounced as */pri:nts/), the resulting variant form was typical of an Italian accent; when the vowel was shortened (e.g., brief pronounced as */brrf/) the resulting variant was an arbitrary variation for an Italian speaker. The variant forms never formed existing Dutch words and were all phonotactically legal in Dutch. All critical items are listed in Appendix B.

As in Experiment 1, an additional 80 words without /i:/ or /I/ were chosen as visual fillers and were paired with primes that represented the correct pronunciation of the filler word, primes that formed a minimal pair, or primes that were unrelated; 160 nonwords paired with primes that formed a minimal pair or with unrelated primes served as nonword filler items. A further 12 targetprime pairs were selected as practice items.

The speaker of the Dutch materials was a female native Italian who had been living in the Netherlands for two years. Her proficiency in Dutch was noticeably lower than the English proficiency of the speaker in Experiment 1 had been, but she knew the pronunciation of most of the stimuli. She had a moderate to strong accent in her pronunciation, that is, the Italian background of the speaker was perceptible on most segments in her speech. Where necessary, a native speaker of Dutch corrected the speaker's productions during the recording session. Multiple tokens for each item were recorded, and the best recording was later selected. Like the Italian speaker in Experiment 1, the speaker in Experiment 2 marked the difference between /i:/ and /I/ not just in duration but also spectrally, as is indeed standard for the Dutch vowel contrast (Adank, van Hout, \& Smits, 2004). As can be seen in Table 6, the vowel in words with short/I/ (e.g., prins) was on average $108 \mathrm{~ms}$ shorter in the canonical vowel forms than in the variant vowel forms, while the vowel in words with long li:/ (e.g., brief) was on average $55 \mathrm{~ms}$ longer in the canonical vowel forms than in the variant vowel forms; the first three formants at the vowel midpoint also differed reliably for canonical and variant vowel forms, with $F 1$ being lower in long vowels than in short vowels, and with both $F 2$ and $F 3$ being higher for long than for short vowels.

As in Experiment 1, primes with short and long vowels were presented in two versions of the experiment, one in which all related primes contained long vowels (e.g., /bri:f/ and */pri:nts/) and one in which all related primes contained short vowels (*/brrf/ and /prrnts/).

\subsubsection{Procedure}

The procedure was the same as in Experiment 1, except for the language of the experiment being Dutch rather than English and the software to control the experiment being NESU rather than the DMDX.

Table 6

Average durations (in $\mathrm{ms}$ ) and formant values (in $\mathrm{Hz}$ ) at vowel midpoint for canonical and variant vowels forms in Experiment 2.

\begin{tabular}{|c|c|c|c|}
\hline & Canonical vowel form & Variant vowel form & Paired $t$-test \\
\hline \multicolumn{4}{|c|}{ /I/ words, e.g., prins } \\
\hline Duration & 94 & 202 & $t(39)=-11.17^{* * *}$ \\
\hline$F 1$ & 456 & 415 & $t(39)=4.01^{* * *}$ \\
\hline$F 2$ & 2699 & 2910 & $t(39)=-5.39^{* * *}$ \\
\hline F3 & 3327 & 3635 & $t(39)=-7.09^{* * *}$ \\
\hline \multicolumn{4}{|c|}{ /i:/ words, e.g., brief } \\
\hline Duration & 173 & 119 & $t(39)=5.51^{\text {**** }}$ \\
\hline F1 & 394 & 513 & $t(39)=-8.96 * *$ \\
\hline $\mathrm{F} 2$ & 2853 & 2408 & $t(39)=9.56^{* * * *}$ \\
\hline F3 & 3521 & 3315 & $t(39)=2.69^{* *}$ \\
\hline
\end{tabular}

**** $p<.001$

$* * p<.01$.

Table 7

Average RTs (in ms) and error rates and standard deviation of error rates (in brackets) for bilingual Dutch-English L1 Listeners in Experiment 2.

\begin{tabular}{lllll}
\hline & \multicolumn{2}{l}{ Genuine Italian accent vowel } & & Arbitrary accent vowel \\
\cline { 2 - 3 } & Canonical /tri:t/ & & Canonical /trik/ \\
\hline Related primes & $521(1.9 \%, 3.47)$ & $558(2.2 \%, 2.56)$ & & $534(1.9 \%, 1.44)$ \\
Unrelated primes & $588(3.3 \%, 4.03)$ & $620(4.1 \%, 5.15)$ & & $590(4.4 \%, 3.22)$ \\
\hline
\end{tabular}




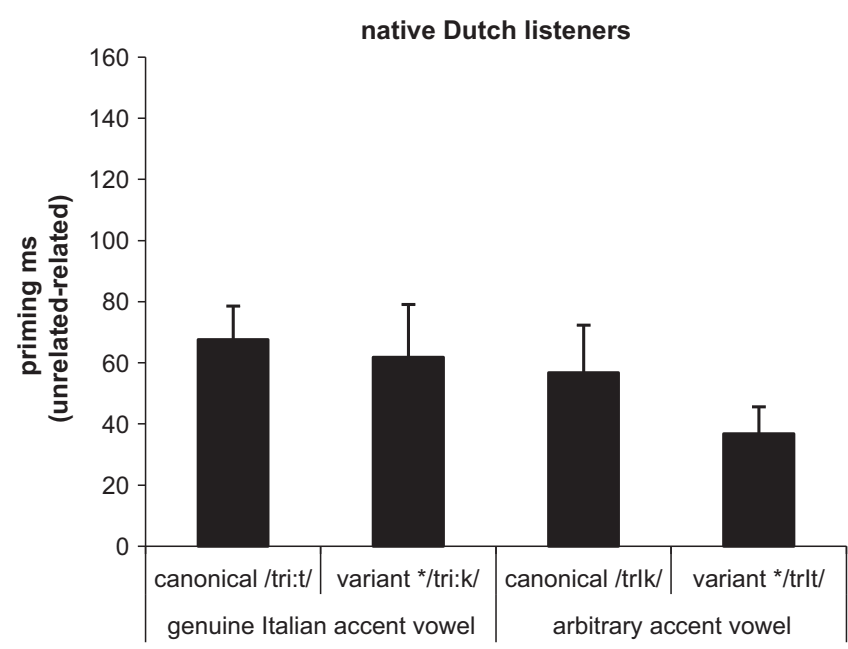

Fig. 4. Priming effects in ms for bilingual Dutch-English L1 listeners in Experiment 2. Error bars represent standard error of the mean.

\subsection{Results and discussion}

Six outliers $(0.2 \%$ of all experimental trials) were removed from the analyses in a way comparable to Experiment 1 . The remaining correct RTs and error rates for each condition are given in Table 7. Calculated priming effects for the RTs are shown in Fig. 4. RTs and error rates were submitted to ANOVAs like those in Experiment 1.

Overall ANOVAs on RTs showed for Dutch L1 listeners a main effect of prime form by participants $\left(F_{1}[1,30]=19.07, p<.001\right.$; $\left.F_{2}<1\right)$ and a main effect of relatedness $\left(F_{1}[1,30]=57.04, p<.001 ; F_{2}[1,78]=75.85 ; p<.001\right)$, as well as a significant interaction by participants between prime form and version $\left(F_{1}[1,30]=7.80, p<.01 ; F_{2}[1,78]=2.46, p>.1\right)$. No other interactions were significant.

The average error rates were low (2.6\% on average). ANOVAs on error rates in Experiment 2 revealed a significant effect of relatedness $\left(F_{1}[1,30]=5.76, p<.05 ; F_{2}[1,78]=75.85 ; p<.001\right)$ with fewer errors being made following related primes than following unrelated primes. No other effects in the error analysis were significant.

When ANOVAs on RTs were run separately for prime forms, main effects of relatedness were found both for canonical vowel forms $\left(F_{1}[1,30]=44.88, p<.001 ; F_{2}[1,78]=60.85 ; p<.001\right)$ and for variant vowel forms $\left(F_{1}[1,30]=24.53, p<.001 ; F_{2}[1,78]=31.47\right.$; $p<.001$ ). Since there were no interactions with version (canonical vowel forms: $F_{1}$ and $F_{2}<1$, variant vowel forms: $F_{1}$ and $F_{2}<1$ ), this suggests that recognition of Dutch words with long and short vowels was not only facilitated by hearing canonical vowel forms but also by hearing genuine- or arbitrarily-accented vowel forms.

In contrast to English L1 listeners in Experiment 1A, Dutch L1 listeners in Experiment 2 recognized arbitrarily accented vowel forms quite easily. The lack of priming for the arbitrarily accented vowel forms in Experiment $1 \mathrm{~A}$ could have been either because the English participants, as native listeners, had detailed knowledge about the accent, or because they, as monolingual listeners, lacked perceptual flexibility. The results of Experiment 2 support the latter interpretation.

This claim is supported by the finding that, for the Dutch L1 listeners (unlike the English L1 listeners), priming for genuinely accented variant forms was as strong as priming for canonical forms. When the genuine Italian variants were compared to their canonical counterparts (between subjects), there was no interaction between relatedness and prime form $\left(F_{1}\right.$ and $\left.F_{2}<1\right)$. When, however, the arbitrary variants were compared to their canonical counterparts, there was a weak interaction between relatedness and prime form $\left(F_{1}[1,30]=4.87 ; p<.05, F_{2}[1,78]=3.00, p>.09\right)$. This possibly suggests that the Dutch L1 listeners' flexibility was still somewhat restricted by whether the accent was genuine or not, though to a much lesser degree than for the English L1 listeners. No such interaction had been found for Dutch listeners when they were performing in their nonnative language in Experiment $1 \mathrm{C}$.

\section{General discussion}

In order to understand foreign-accented speech, listeners must learn to handle non-canonical pronunciations. The present study investigated to what degree adaptation to foreign accents is constrained by the genuineness of accent markers, and if and how prior language experience influences how listeners adapt. In two-cross modal priming studies, L1 and L2 listeners were presented with auditory primes that were either spoken with canonical vowels, or contained vowel substitutions that were typical or atypical of the accent of Italian L2 speakers. A genuine (typical) Italian accent marker is lengthening of the short vowel/I/ in English words such as trick and Dutch words such as prins, and an arbitrary (atypical) accent marker is the shortening of the long vowel /i:/ in English words such as treat and Dutch words such as brief.

In Experiment 1, English L1 listeners showed priming for variant forms with Italian vowel lengthening (e.g., trick pronounced */tri:k/), but failed to do so for variant forms with arbitrary vowel shortening (e.g., treat pronounced */trit/). Italian L2 listeners accepted both variant forms and showed facilitatory priming for words with vowel lengthening and for words with vowel shortening. We have argued that this is because Italians cannot reliably distinguish vowel length. Furthermore, and for the same reason, both types of variant form produced 
priming in the Italian listeners that was as strong as that produced by the canonical pronunciations of these words. Dutch listeners, in contrast, showed more flexibility in their adaptation to the variant forms: When tested in their L2 English (Experiment 1) and when tested in their L1 Dutch (Experiment 2), they interpreted both the Italian vowel variants and the arbitrary vowel variants correctly. Furthermore, for the Dutch listening to L2 English, as for the English L1 listeners (but unlike the Italian L2 listeners), both variant forms were more difficult to recognize than their canonical counterparts.

Italian listeners interpreted all variant forms correctly, regardless of their authenticity. Even though one can assume that no other listener group is as familiar with the Italian accent as Italian speakers are, seemingly this did not lead to an advantage of Italian variants over arbitrary variants. For Italian listeners, however, this insensitivity is almost certainly driven by general perceptual difficulties with distinguishing vowel length (e.g., Flege et al., 1999). Such an influence of perceptual discrimination abilities is in line with previous findings. Weber et al. (2011) have shown that variant forms that are atypical of the L2 listeners' own accent can still facilitate word recognition if they are perceptually confusable with the canonical form for the L2 listeners (e.g., Dutch-accented [penda] is confusable with the canonical English form [pænda] for Japanese listeners and facilitates recognition of panda even though [penda] is not representative for a Japanese accent). While the perceptual difficulties with vowel length were beneficial for the Italian listeners in the present study (i.e., they interpreted more words correctly than the English L1 listeners did) it can of course quickly turn into a disadvantage. Italian listeners are likely to erroneously interpret bitch as beach or fit as feet.

In Experiment 1, Dutch L2 listeners adapted to forms with arbitrarily accented vowels but English L1 listeners did not. This could have implied that L2 listeners are generally less sensitive to the genuineness of a foreign accent than L1 listeners are and therefore adapt more readily to variant forms that are not typical for the accent of the speaker. But this interpretation was challenged in Experiment 2, when Dutch listeners also correctly interpreted forms with arbitrarily accented vowels when they were performing in their native language Dutch. The explanation for the difference between the Dutch and English listeners that we favor, therefore, is based on the fact that Dutch speakers are highly multilingual, while English speakers often are not. For example, in the IMD world competitiveness yearbook (IMD, 2011) which ranks the competitiveness of nations based on business and government efficiency, the multilingual language skills of the Dutch are ranked in the top tier while the United Kingdom is ranked considerably lower. Consistent with these national differences, all Dutch participants in the present study listed at least three foreign languages in the language background questionnaire, while only $12.5 \%$ of the British English participants indicated that they could speak and understand a foreign language. Multilinguality entails being used to learning new pronunciations but also being used to varying word forms for highly similar concepts (e.g., minute pronounced as /minit/ in English and as /minyt/ in French). These two factors could positively influence how easily multilingual listeners can handle variation in foreign-accented speech.

We suggest, therefore, that bilingualism enhances flexibility in spoken-word recognition. The requirement of having to mentally juggle two (or more) languages has been proposed as the driving force behind the enhanced cognitive control in non-linguistic tasks shown by bilinguals, including 4-to-5-year-old bilingual children (Bialystok, 2009; Bialystok \& Martin, 2004). The need to be able to switch rapidly between speaking one language and speaking another is likely to be why bilinguals can also switch so rapidly from producing the phonetic characteristics of one of their languages to producing those of their other language (Grosjean \& Miller, 1994). The present findings add to evidence that the experience of becoming and remaining bilingual has consequences not only for flexibility in cognitive control and speech production, but also in speech recognition (for a recent overview on this topic see e.g., Bialystok, 2009). Bilingual infants (17-month-olds) can learn words that were produced by speakers of the infants' two languages better than monolingual infants (Mattock et al., 2010). This flexibility in how early bilinguals cope with variability in phonetic detail in lexical processing apparently extends to the late bilinguals studied here, in the way they deal with the phonetic variability inherent in foreign-accented speech. Although bilinguals appear not to be better than monolinguals in discriminating the phonetic categories of an unknown language (Werker, 1986), this may simply suggest that there are limitations on the perceptual flexibility of bilinguals. It may be that experience with different pronunciations (within and between languages) leads to greater flexibility in mapping those variable signals onto the mental lexicon, but not to enhancements in the ability to discriminate unknown phonetic categories. The prior experience of the bilinguals is, after all, with variation within established phonological systems, and not with novel phonetic contrasts.

Note that Maye, Aslin, \& Tanenhaus (2008) tested American listeners' ability to adapt to English words with front vowel lowering (e.g., witch pronounced as /wet//), and found that American listeners more readily accepted variant forms with lowered vowels as words after having listened to a 20-min story with front vowel lowering. Thus, even though American listeners, just like British English listeners, are probably less multilingual than Dutch listeners are, they nevertheless adapted to variant pronunciations during the course of an experiment. This does not contradict our results for arbitrary forms, however, for two reasons. First, the exposure phase in Maye et al. (2008) was considerably longer than our experiment was. Second, the accent in Maye et al. was modeled on a familiar regional dialect of American English and so was not an arbitrary change. Nevertheless, it is important to note that we are not arguing that monolingual listeners are unable to adapt to arbitrary forms of foreign-accented speech, only that bilingual (and multilingual) listeners have greater perceptual flexibility.

This flexibility hypothesis suggests that broad linguistic experience (as measured, e.g., by how many languages one can understand) shapes the plasticity of the speech-perception system. The results of Experiment $1 \mathrm{~A}$ indicate a more specific effect of prior linguistic experience on interpretation of variant pronunciations. Recall that there was a difference between the two types of variant: Words with arbitrarily accented vowels did not facilitate word recognition for L1 English listeners while words with genuinely accented vowels did. Lack of experience with the arbitrarily accented vowel words could either be because none of the prevailing foreign accents in England happens to shorten the long vowel /i:/ and therefore English listeners are in general not familiar with vowel shortening, or more particularly because speakers of the well-known Italian accent typically do not shorten long vowels. The present 
study cannot disentangle these two possibilities, although it is known that speakers of a variety of accents typically confuse long and short vowels (see e.g., Flege, Bohn, \& Jang, 1997), but it does suggest that linguistic experience within monolingual listener groups also shapes perceptual flexibility.

The English canonical vowel forms were always recognized more easily than the variant forms, even when the variant forms themselves significantly facilitated target word recognition (e.g., for English L1 listeners, both */tri:k/ and /trrk/ facilitated recognition of trick, but canonical /trtk/ primed more strongly). Only the Italian L2 listeners had no advantage for the canonical English forms, but that is most probably because they had perceptual difficulties with vowel length. The L1 Dutch listeners in Experiment 2 did not show this canonical advantage, we would argue because of their greater flexibility arising from their experience as bilingual speakers.

The fact that English L1 listeners recognized canonical forms more easily than variant forms is in line with research on L1 word recognition in dialects (e.g., Maye et al., 2008; Sumner \& Samuel, 2009), on intelligibility of foreign accents for L1 listeners (e.g., Bent \& Bradlow, 2003; van Wijngaarden, 2001), and on recognition of words with multiple pronunciation variants (e.g., McLennan, Luce, \& Charles-Luce, 2003; Pitt, Dilley, \& Tat, 2011; Ranbom \& Connine, 2007). Canonical forms can be recognized faster even when variant forms occur more frequently than those canonical forms in everyday speech (e.g., Connine, Ranbom, \& Patterson, 2008). We note, however, that some studies have not found an advantage for canonical forms (e.g., Gow, 2001, 2002), and even that some studies have found a canonical advantage on only some measures (e.g. an advantage in long-term but not immediate processing; Sumner \& Samuel, 2005). It thus appears that the presence of a canonical advantage may depend on both the nature of the pronunciation variant and the task used to assess it. The present findings suggest that there is such an advantage in immediate priming with foreign-accented speech, and that its presence may also depend on the nature of the participants: Bilingual Dutch listeners, processing Dutch, appear to show no canonical advantage, whereas monolingual English listeners do when they are processing English.

For L2 listeners, we know only from offline intelligibility studies that L2 listeners can find foreign-accented speech as intelligible as native speech, and some studies have even found that L2 listeners find foreign-accented speech from speakers with varying language backgrounds equally intelligible (e.g., Bent \& Bradlow, 2003; Munro et al.,2010; van Wijngaarden, 2001; van Wijngaarden, Steeneken, \& Houtgast, 2002), although others studies have failed to find effects of mutual intelligibility of foreign-accented speech (e.g., Leikin, Ibrahim, Eviatar, \& Sapir, 2009; Stibbard \& Lee, 2006). The results of Italian and Dutch L2 listeners in the present study can help to qualify the above findings on intelligibility as they suggest that there is no advantage for canonical forms in L2 processing when listeners have perceptual difficulties discriminating canonical forms and variant forms (i.e., the Italians), but that there is a clear advantage of canonical forms for L2 listeners who do not have perceptual discrimination difficulties (i.e., the Dutch). An advantage of canonical forms for L2 listeners is not self-evident; L2 listeners who had learned the second language while being resident in their native country (as the Dutch L2 listeners in the present study had) probably encountered accented forms early and plentifully during L2 acquisition.

\section{Conclusion}

We draw three conclusions about adaptation to foreign-accented speech. First, and most generally, listeners can accommodate to accent characteristics, as demonstrated by their ability to recognize English words spoken with Italian accented vowels (e.g., trick pronounced */tri:k/). Thus the fact that the language background of a nonnative speaker is perceptible on most segments of his or her speech does not hinder accommodation to specific accent characteristics. Second, this ability is not limited to native listeners. In spite of the fact that processing in L2 is generally more difficult and slower than in L1, nonnative Italian and Dutch listeners were also able to recognize the English words with Italian accented vowels. In addition, the nonnative Dutch listener data suggest that experience with foreign-accented speech in one language (i.e., Italian-accented Dutch) can lead to benefits in recognizing accented words in another language (Italian-accented English). Long-term prior experience with accented speech thus establishes a phonetic-to-lexical mapping that can be applied not only to new speakers of that accent (as previously shown by Witteman et al., 2013) but also to speakers of similar accents in other languages. Third, long-term experience with multiple languages (and probably also with multiple accents) plays another role in determining the flexibility of listeners' responses to foreign-accented speech. The Dutch listeners, who were Dutch-English bilinguals, were able to adapt to and hence recognize the arbitrarily-accented words (e.g., treat pronounced */trrt/), and could do so in both their languages; the monolingual English listeners did not adapt to these words. We suggest that bilingualism enhances flexibility in the phonetic-to-lexical mapping that is required for listeners to be able to recognize words in different types of foreign-accented speech.

\section{Acknowledgments}

This research was supported by the Minerva 2 program of the Max Planck Society awarded to the first author, and a research visit grant from British Council and Platform Beta Techniek awarded to the second author (ref: PPS RV012). We want to thank Laurence Bruggeman, Karina Visser, and Anne Blankenhorn for research assistance.

\section{Appendix A}


Table A1

English experimental stimuli used in Experiment 1.

\begin{tabular}{|c|c|c|c|}
\hline Targets with /i/ & Canonical prime & Arbitrarily-accented prime & Unrelated prime \\
\hline ACHIEVE & /ə'tfi:v/ & /a'tyiv/ & wagon \\
\hline BEAST & /'bi:st/ & /'bist/ & womb \\
\hline BEEF & /'bi:f/ & /'brf/ & ward \\
\hline BEETLE & /'bi:tl/ & /'brtt/ & writer \\
\hline BREATHE & /'bri:ð/ & /'brıð/ & poem \\
\hline CANTEEN & /kæn'ti:n/ & /kæn'tin/ & master \\
\hline CHEESE & /'tfi:zl & /'tfizl & phase \\
\hline CHIEF & /'tfi:f/ & /'tfrf/ & rush \\
\hline CLEAN & /'kli:n/ & /'klin/ & mute \\
\hline CONCEAL & /kən'si:l/ & /kən'si:l/ & notion \\
\hline CREAM & /'kri:m/ & /'krIm/ & bird \\
\hline DREAM & /'dri:m/ & /'drim/ & round \\
\hline EAGLE & /'i:gl/ & /'Igi/ & afford \\
\hline FEED & /'fi:d/ & /'fid/ & mood \\
\hline FREEDOM & /'fri:dəm/ & /'fridem/ & bramble \\
\hline GLEAM & /'gli:m/ & /'glim/ & cage \\
\hline GREEK & /'gri:k/ & /'grrk/ & climb \\
\hline GRIEF & /'gri:f/ & /'grrf/ & wipe \\
\hline LEAF & /'li:f/ & /'Irf/ & pram \\
\hline LEAGUE & /'li:g/ & /'Irg/ & juice \\
\hline NEED & /'ni:d/ & /'nId/ & trunk \\
\hline ORDEAL & /J:'di:l/ & /o:'drl/ & yellow \\
\hline PEANUT & /'pi:n^t/ & /'pin^t/ & burden \\
\hline PLEAD & /'pli:d/ & /'plid/ & sign \\
\hline PLEASE & |'pli:z| & /'plız/ & south \\
\hline PREACH & /'pri:t// & /'pritg/ & corn \\
\hline PRIEST & /'pri:st/ & /'prrst/ & strike \\
\hline SCREEN & /'skri:n/ & /'skrin/ & cross \\
\hline SEASON & /'si:zn/ & /'sIzn/ & brother \\
\hline SEIZE & /'si:z/ & /'sIz/ & coast \\
\hline SLEEVE & /'sli:v/ & /'sliv/ & youth \\
\hline SPEECH & /'spi:t// & /'spit// & chap \\
\hline SPEED & /'spi:d/ & /'spid/ & lover \\
\hline SQUEEZE & /'skwi:z/ & /'skwIz & pride \\
\hline STREET & /'stri:t/ & /'strit/ & ape \\
\hline SWEEP & /'swi:p/ & /'swip/ & draft \\
\hline SWEET & /'swi:t/ & /'swit/ & rain \\
\hline TEACHER & /'ti:ţa/ & /'trtfə/ & meadow \\
\hline TREAT & /'tri:t/ & /'trrt/ & odd \\
\hline WEED & /'wi:d/ & /'wId/ & screw \\
\hline Targets with /I/ & Canonical prime & Italian accented prime & Unrelated prime \\
\hline BILL & /'bil/ & /'bi:l/ & palm \\
\hline BRIDGE & /'bridz/ & /'bri:dz/ & dull \\
\hline BRING & /'brin/ & /'bri:y/ & scale \\
\hline BUILD & /'brld/ & /'bi:Id/ & tongue \\
\hline CHILL & /'tfIl/ & /'tfi:l/ & bible \\
\hline $\mathrm{CHIN}$ & /'tin/ & /'tfi:n/ & slight \\
\hline CLIFF & /'klıf/ & /'kli:f/ & broke \\
\hline DISH & /'dIf/ & /'di:f/ & block \\
\hline FRINGE & /'frindz/ & /'fri:ndz/ & pike \\
\hline GIGGLE & /'gigi/ & /'gi:gl/ & contract \\
\hline GIVE & /'giv/ & l'gi:v/ & giant \\
\hline GUILT & /'gilt/ & /'gi:lt/ & sharp \\
\hline KISS & /'kIs/ & /'ki:s/ & yard \\
\hline LISTEN & /'Issn/ & /'li:sn/ & storage \\
\hline MIDDLE & /'mIdl// & /'mi:dl/ & expense \\
\hline MILK & /'mIlk/ & /'mi:lk/ & joke \\
\hline NIPPLE & /'nipl/ & /'ni:pl/ & journal \\
\hline $\mathrm{PINCH}$ & /'prnt// & /'pi:nty/ & laid \\
\hline PREDICT & /pri'drkt/ & /pri:'dIkt/ & danger \\
\hline QUICK & /'kwIk/ & /'kwi:k/ & wild \\
\hline SHIFT & l'frft/ & /'fi:ft/ & taught \\
\hline SHRINK & l'Jrsnk/ & /'fri:nk/ & host \\
\hline SING & /'sink/ & /'si:nk/ & brain \\
\hline SINGLE & /'singl/ & /'si:ngl/ & narrow \\
\hline SKIN & /'skIn/ & /'ski:n/ & folk \\
\hline SPLIT & /'split/ & /'spli:t/ & craft \\
\hline SPRINKLE & /'sprinkl/ & /'spri:nkl/ & silence \\
\hline STIFF & /'strf/ & /'sti:f/ & ranch \\
\hline SWIFT & /'swift/ & /'swi:ft/ & uncle \\
\hline THICK & /'OIk/ & /' $\theta \mathrm{i}: \mathrm{k} /$ & flash \\
\hline TRICK & /'trak/ & /'tri:k/ & store \\
\hline TRIGGER & /'trigə/ & /'tri:gə/ & handsome \\
\hline
\end{tabular}


Table A1 (continued)

\begin{tabular}{|c|c|c|c|}
\hline Targets with /i/ & Canonical prime & Arbitrarily-accented prime & Unrelated prime \\
\hline TWIN & /'twin/ & /'twi:n/ & rice \\
\hline TWITCH & /'twitg/ & /'twi:t// & crop \\
\hline WHISTLE & /'WIsl// & /'wi:sl/ & thyroid \\
\hline WING & /'WIn/ & /'wi:y/ & trust \\
\hline WISH & /'wIJ/ & /'wi: $/ /$ & barn \\
\hline WITCH & /'wit// & /'wi:t/ & ale \\
\hline WRINKLE & /'rıjnkl/ & /'ri:nkl/ & northern \\
\hline WRIST & /'rist/ & /'ri:st/ & blonde \\
\hline
\end{tabular}

\section{Appendix B}

\section{See Table B1.}

Table B1

Dutch experimental stimuli used in Experiment 2.

\begin{tabular}{|c|c|c|c|}
\hline Targets with /i/ & Canonical prime & Arbitrarily-accented prime & Unrelated prime \\
\hline ADVIES & /at'fi:s/ & /at'fis/ & fornuis \\
\hline ANTIEK & /an'ti:k/ & /an'trk/ & meloen \\
\hline BIER & /'bi:r/ & /'bir/ & huid \\
\hline BIZON & /'bi:zon/ & /'bizon/ & hulde \\
\hline BRIEF & /'bri:f/ & /'brrf/ & kers \\
\hline DIENST & /'di:nst/ & /'dinst/ & teer \\
\hline DIER & /'di:r/ & /'dir/ & kroeg \\
\hline FIETS & /'fi:ts/ & /'frts/ & snor \\
\hline KIES & /'ki:s/ & /'kIs/ & homp \\
\hline KIEZEL & /'ki:zəl// & /'kızəl/ & lotto \\
\hline KIEZEN & /'ki:zə/ & /'kızə/ & emmer \\
\hline KWARTIER & /kwar'ti:r/ & /kwar'tır/ & steunen \\
\hline LIEF & /li:f/ & /'IIf/ & spuit \\
\hline MANIER & /ma:'ni:r/ & /ma:'nrr/ & peper \\
\hline MIER & /'mi:r/ & /'mIr/ & wraak \\
\hline MOTIEF & /mo:'ti:f/ & /mo:trf/ & censuur \\
\hline MYTHE & /'mi:tə/ & /'mItə/ & afwas \\
\hline NIER & /'ni:r/ & /'nIr/ & juk \\
\hline NIEZEN & /'ni:zə/ & /'nize/ & erker \\
\hline PANIEK & /pa:'ni:k/ & /pa:'nIk/ & majoor \\
\hline PAPIER & /pa:'pi:r/ & /pa:'pır/ & talent \\
\hline PIEPEN & /'pi:pə/ & /'рірә/ & stekel \\
\hline PLEZIER & /plə'zi:r/ & /plə'zir/ & abdij \\
\hline PUBLIEK & /py:'bli:k/ & /py:'blık/ & slapen \\
\hline RIEM & /'ri:m/ & /'rrm/ & kaft \\
\hline SCHIETEN & /'sxi:tə/ & /'sxitə/ & ijzer \\
\hline SERVIES & /scr'vi:s/ & /sEr'vIS/ & kameel \\
\hline SIERAAD & /'si:ra:t/ & /'sIra:t/ & dokter \\
\hline SIERLIJK & /'si:rlək/ & /'sIrlək/ & plaksel \\
\hline SPIER & /'spi:r/ & /'spir/ & vak \\
\hline STATIEF & /sta:'ti:f/ & /sta:'trf/ & boeket \\
\hline STIER & /'sti:r/ & /'strr/ & oogst \\
\hline TEXTIEL & /tek'sti:l/ & /tck'strl/ & roman \\
\hline TITEL & /'ti:təl/ & /'trtəl// & maaltijd \\
\hline VENTIEL & /ven'ti:I/ & /ven'trl// & tapijt \\
\hline VERDRIET & /vər'dri:t/ & /vər'dit/ & acteur \\
\hline VIERKANT & /'vi:rkant/ & /'virkant/ & bloesem \\
\hline VIRUS & /'vi:rys/ & /'VIrYs/ & bamboe \\
\hline VRIEZEN & /'vri:zə/ & /'vrrze/ & foto \\
\hline ZIEKTE & /'zi:ktə/ & /'ziktə/ & modder \\
\hline Targets with /I/ & Canonical prime & Italian-accented prime & Unrelated prime \\
\hline APRIL & /a'pril/ & /a'pri:|/ & buro \\
\hline BACIL & /ba:'sil/ & /ba:'si:l/ & soldaat \\
\hline BASSIST & /ba'sist/ & /ba'si:st/ & factuur \\
\hline BEWIND & /bə'wint/ & /bə'wi:nt/ & toneel \\
\hline BLIK & /'blik/ & /'bli:k/ & staan \\
\hline BLIKSEM & /'blıksəm/ & /'bli:ksəm/ & eikel \\
\hline BLIND & /'blint/ & /'mli:nt/ & rouw \\
\hline CIRKEL & /'sırkəl/ & /'si:rkəl/ & hertog \\
\hline CONFLICT & /kon'flıkt/ & /kon'fli:kt/ & sopraan \\
\hline CURSIST & /kyr'sist/ & /kyr'si:st/ & tabak \\
\hline
\end{tabular}


Table B1 (continued)

\begin{tabular}{|c|c|c|c|}
\hline Targets with /i/ & Canonical prime & Arbitrarily-accented prime & Unrelated prime \\
\hline DELICT & /de:'Irkt/ & /de:'li:kt/ & buffet \\
\hline $\mathrm{DICHT}$ & /'dixt/ & /'di:xt/ & jas \\
\hline DING & /'dIn/ & /'di:y/ & kruis \\
\hline FILM & /'frlm/ & /'fi:Im/ & schuin \\
\hline GEDICHT & /xə'dIxt/ & /xə'di:xt/ & pastoor \\
\hline GRAVIN & /xra:'vin/ & /xra:'vi:n/ & dolfijn \\
\hline HITTE & /'hrtə/ & /'hi:tə/ & mosterd \\
\hline INHOUD & /'Inhaut/ & /'i:nhaut/ & lasso \\
\hline INKT & /'Inkt/ & /'i:nkt/ & luik \\
\hline KLIMMEN & /'klımə/ & /'kli:mə/ & omroep \\
\hline KLINKER & /'klinkər/ & /'kli:nkər/ & huren \\
\hline KLIP & /'klip/ & /'kli:p/ & hand \\
\hline KNIKKER & /'knikər/ & /'kni:kər/ & wortel \\
\hline KOKKIN & /ko'kIn/ & /ko'ki:n/ & natuur \\
\hline KRING & /'krrn/ & /'kri:n/ & hok \\
\hline LIFT & /'Ift/ & /'li:ft/ & markt \\
\hline MIST & /'mist/ & /'mi:st/ & koorts \\
\hline NARCIS & /nar'sis/ & /nar'si:s/ & galop \\
\hline PINDA & /'pinda:/ & /'pi:nda:/ & rooster \\
\hline PRINS & /'prins/ & /'pri:ns/ & storm \\
\hline PUPIL & /py:'pil/ & /py:'pi:I/ & framboos \\
\hline RIMPEL & /'rumpəl/ & /'ri:mpəl/ & stempel \\
\hline RITS & /'rts/s/ & /'ri:ts/ & herfst \\
\hline STILTE & /'strltə/ & /'sti:Itə/ & kaneel \\
\hline TOERIST & /tu:'rrst/ & /tu:'ri:st/ & lakei \\
\hline VERSTRIKT & /vər'strakt/ & /vər'stri:kt/ & bestuur \\
\hline VINGER & /'vinər/ & /'vi:nər/ & koepel \\
\hline WINKEL & /'wInkəl/ & /'wi:nkəl/ & matroos \\
\hline WINTER & /'wintər/ & /'wi:ntər/ & keuren \\
\hline ZILVER & /'zilvər/ & l'zi:Ivər/ & pleister \\
\hline
\end{tabular}

\section{References}

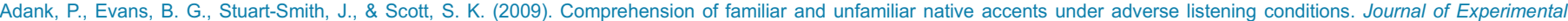
Psychology: Human Perception and Performance, 35, 520-529.

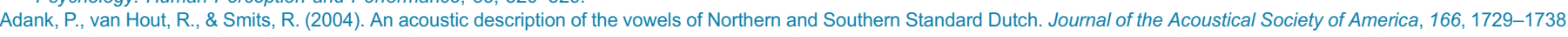
Agard, F., \& di Pietro, R. (1969). The sounds of English and Italian: A systematic analysis of the contrasts between the sound systems. Chicago: University of Chicago Press. Andruski, J. E., Blumstein, S. E., \& Burton, M. (1994). The effect of subphonemic differences on lexical access. Cognition, 52, 163-187.

Bent, T., \& Bradlow, A. R. (2003). The interlanguage speech intelligibility benefit. The Journal of the Acoustical Society of America, 114, 1600-1610.

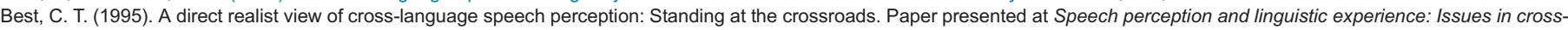
language research, Baltimore.

Bialystok, E. (2009). Bilingualism: The good, the bad, and the indifferent. Bilingualism: Language and Cognition, 12, 3-11.

Bialystok, E., \& Martin, M. M. (2004). Attention and inhibition in bilingual children: Evidence from the dimensional change card sort task. Developmental Science, 7, 325-339.

Boersma, P. (2001). Praat, a system for doing phonetics by computer. Glot International, 5, 341-345.

Bohn, O. S., \& Munro, M. J. (Eds.). (2007). Language experience in second language speech learning: In honor of James Emil Flege. Amsterdam: John Benjamins.

Bradlow, A. R., \& Bent, T. (2008). Perceptual adaptation to non-native speech. Cognition, 106, 707-729.

Clarke, C. M., \& Garrett, M. F. (2004). Rapid adaptation to foreign-accented English. The Journal of the Acoustical Society of America, 116, 3647-3658.

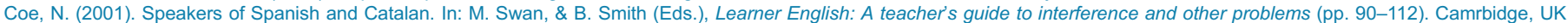
Cambridge University Press.

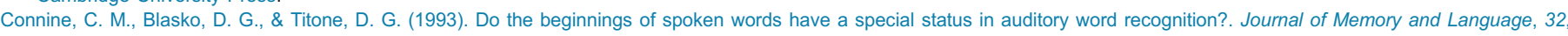
193-210.

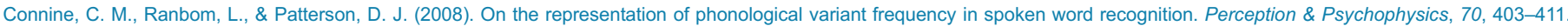

Cristia, A., Seidl, A., Vaughn, C., Schmale, R., Bradlow, A., \& Floccia, C. (2012). Linguistic processing of accented speech across the lifespan. Frontiers in Psychology, 3 , 479.

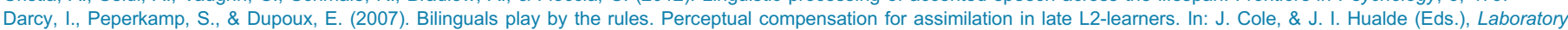
phonology, Vol. 9 (pp. 411-442). Berlin: Mouton de Gruyter.

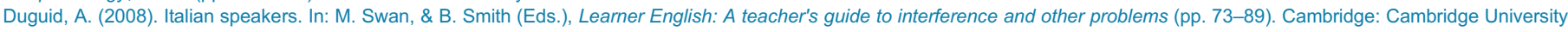
Press.

Ferrero, F., Magno Caldognetto, E., Vagges, K., \& Lavagnoli, C. (1978). Some acoustic characteristics of the Italian vowels. Journal of Italian Linguistics, 3, 87-95.

Flege, J. E., \& Bohn, O.-S. (1997). Effects of experience on non-native speakers' production and perception of English vowels. Journal of Phonetics, $25,437-470$.

Flege, J. E., Bohn, O.-S., \& Jang, S. (1997). Effects of perception on non-native speakers' production and perception of English vowels. Journal of Phonetics, 25, 437-470.

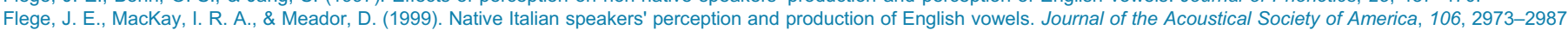

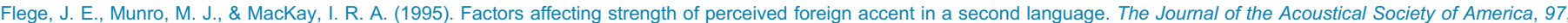
3125-3134.

Floccia, C., Butler, J., Goslin, J., \& Ellis, L. (2006). Regional and foreign accent processing in English: can listeners adapt). Journal of Psycholinguistic Research, 38, 379-412.

Forster, K. I., \& Forster, J. C. (2003). DMDX: A windows display program with millisecond accuracy. Behavior Research Methods, Instruments, \& Computers, 35, 116-124.

Giegerich, H. J. (1992). English phonology: An introduction. Cambridge: Cambridge University Press.

Gow, D. W. (2001). Assimilation and anticipation in continuous spokenword recognition. Journal of Memory \& Language, 45, 133-159.

Gow, D. W. (2002). Does English coronal place assimilation create lex-ical ambiguity?. Journal of Experimental Psychology: Human Perception \& Performance, 28, 163-179.

Grosjean, F. \& Miller, J. L. (1994). Going in and out of languages: An example of bilingual flexibility. Psychological Science, 5, 201-206.

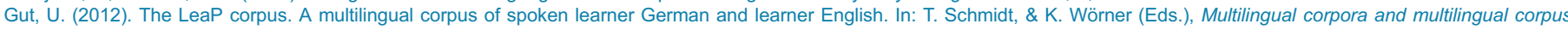
analyses (pp. 3-23). Amsterdam: John Benjamins.

IMD (2011). World Competitiveness Yearbook (WCY). 〈http://www.imd.org/research/publications/wcy/wcy_online.cfm〉.

Kraljic, T., \& Samuel, A. G. (2005). Perceptual learning for speech: Is there a return to normal?. Cognitive Psychology, 51, 141-178.

Kraljic, T., Samuel, A. G., \& Brennan, S. E. (2008). First impressions and last resorts: How listeners adjust to speaker variability. Psychological Science, $19,332-338$. 


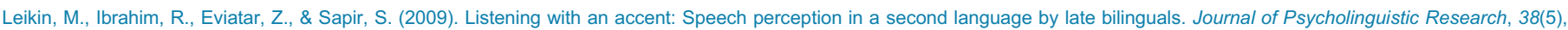
$447-457$.

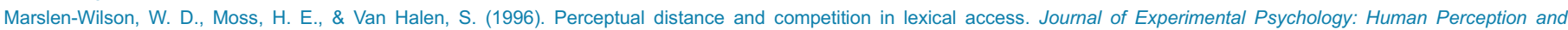
Performance, 22, 1376-1392.

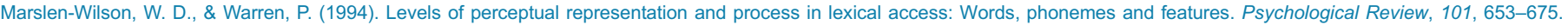

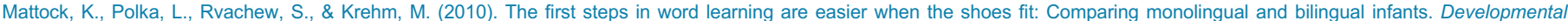
Science, 13, 229-243.

Maye, J., Aslin, R. N., \& Tanenhaus, M. K. (2008). The weckud wetch of the wast: Lexical adaptation to a novel accent. Cognitive Science, 32, 543-562.

McLennan, C. T., Luce, P. A., \& Charles-Luce, J. (2003). Representation of lexical form. Journal of Experimental Psychology: Learning, Memory, \& Cognition, 29 , 539-553.

McQueen, J. M., Cutler, A., \& Norris, D. (2006). Phonological abstraction in the mental lexicon. Cognitive Science, 30, 1113-1126.

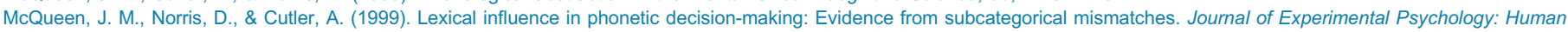
Perception and Performance, 25, 1363-1389.

Munro, M. J., Derwing, T. M., \& Burgess, C. (2010). Detection of nonnative speaker status from content-masked speech. Speech Communication, 52, 626-637.

Norris, D., McQueen, J. M., \& Cutler, A. (2003). Perceptual learning in speech. Cognitive Psychology, 47, $204-238$.

Paap, K. R., \& Greenberg, Z. I. (2013). There is no coherent evidence for a bilingual advantage in executive processing. Cognitive Psychology, 66, 232-258.

Pitt, M. A., Dilley, L., \& Tat, M. (2011). Exploring the role of exposure frequency in recognizing pronunciation variants. Journal of Phonetics, 39, 304-311.

Ranbom, L. J., \& Connine, C. M. (2007). Lexical representation of phonological variation in spoken word recognition. Journal of Memory and Language, 57, 273-298.

Scott, D. R., \& Cutler, A. (1984). Segmental phonology and the perception of syntactic structure. Journal of Verbal Learning and Verbal Behavior, $23,450-466$.

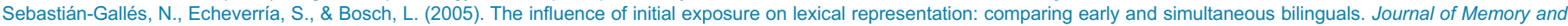
Language, 52(2), 240-255.

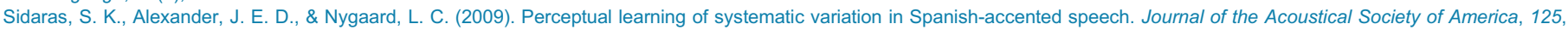
3306-3316.

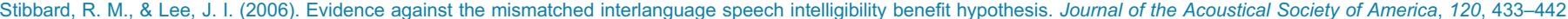

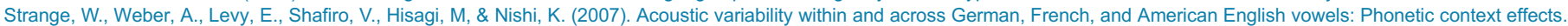
The Journal of the Acoustical Society of America, 122, 1111-1129.

Sumner, M., \& Samuel, A. G. (2005). Perception and representation of regular variation: The case of final /t/. Journal of Memory and Language, 52, 322-338.

Sumner, M. \& Samuel, A. G. (2009). The effect of experience on the perception and representation of dialect variants. Journal of Memory and Language, 60, 487-501.

van der Feest, S., \& Swingley, D. (2011). Dutch and English listeners' interpretation of vowel duration. Journal of the Acoustical Society of America, 129, EL57-EL63.

van Wijngaarden, S. J. (2001). Intelligibility of native and non-native Dutch speech. Speech Communication, 35, $103-113$.

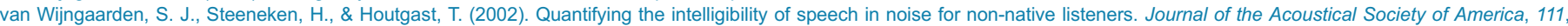
1906-1916.

Weber, A., Broersma, M., \& Aoyagi, M. (2011). Spoken-word recognition in foreign-accented speech by L2 listeners. Journal of Phonetics, 39 , $479-491$.

Weber, A., \& Cutler, A. (2004). Lexical competition in non-native spoken-word recognition. Journal of Memory and Language, 50, 1-25.

Werker, J. F. (1986). The effect of multilingualism on phonetic perceptual flexibility. Applied Psycholinguistics, 7, 141-156.

Whalen, D. H. (1991). Subcategorical phonetic mismatches and lexical access. Perception \& Psychophysics, 50, 351-360

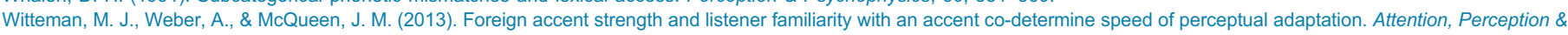
Psychophysics, 75, 576-587. 